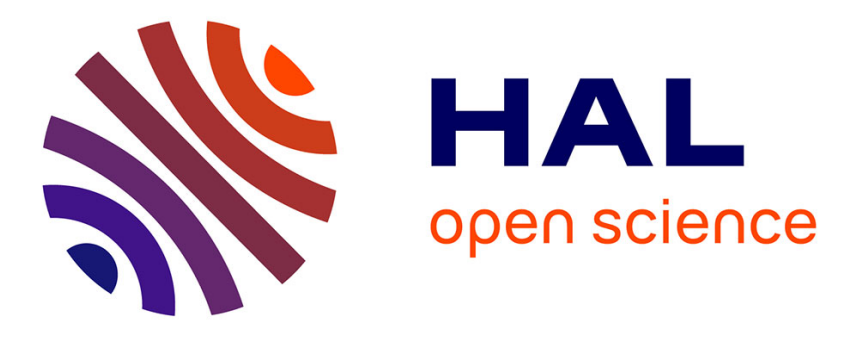

\title{
Structure and assembly of archaeal viruses
}

Diana Baquero, Ying Liu, Fengbin Wang, Edward Egelman, David

Prangishvili, Mart Krupovic

\section{To cite this version:}

Diana Baquero, Ying Liu, Fengbin Wang, Edward Egelman, David Prangishvili, et al.. Structure and assembly of archaeal viruses. Advances in Virus Research, 108, pp.127-164, 2020, Virus Assembly and Exit Pathways, 10.1016/bs.aivir.2020.09.004 . pasteur-03112956

\section{HAL Id: pasteur-03112956 https://hal-pasteur.archives-ouvertes.fr/pasteur-03112956}

Submitted on 18 Jan 2021

HAL is a multi-disciplinary open access archive for the deposit and dissemination of scientific research documents, whether they are published or not. The documents may come from teaching and research institutions in France or abroad, or from public or private research centers.
L'archive ouverte pluridisciplinaire HAL, est destinée au dépôt et à la diffusion de documents scientifiques de niveau recherche, publiés ou non, émanant des établissements d'enseignement et de recherche français ou étrangers, des laboratoires publics ou privés. 


\section{Structure and assembly of archaeal viruses}

Diana P. Baquero ${ }^{1,2}$, Ying Liu ${ }^{1}$, Fengbin Wang ${ }^{3}$, Edward H. Egelman ${ }^{3}$, David Prangishvili ${ }^{1,4}$, Mart Krupovic $^{1 *}$

${ }^{1}$ Archaeal Virology Unit, Department of Microbiology, Institut Pasteur, France

${ }^{2}$ Sorbonne Université, Collège doctoral, F-75005 Paris, France

${ }^{3}$ Department of Biochemistry and Molecular Genetics, University of Virginia, Charlottesville, VA 22908, USA

${ }^{4}$ Ivane Javakhishvili Tbilisi State University, 0179 Tbilisi, Georgia

* Corresponding author:

E-mail: mart.krupovic@pasteur.fr 


\begin{abstract}
Viruses of archaea represent one of the most enigmatic parts of the virosphere. Most of the characterized archaeal viruses infect extremophilic hosts and display remarkable diversity of virion morphotypes, many of which have never been observed among bacteriophages or viruses of eukaryotes. However, recent environmental studies have shown that archaeal viruses are widespread also in moderate ecosystems, where they play an important ecological role by influencing the turnover of microbial communities, with a global impact on the carbon and nitrogen cycles. In this review, we summarize recent advances in understanding the molecular details of virion organization and assembly of archaeal viruses. We start by briefly introducing the 20 officially recognized families of archaeal viruses and then outline the similarities and differences of archaeal virus assembly with the morphogenesis pathways used by bacterial and eukaryotic viruses, and discuss the evolutionary implications of these observations. Generally, the assembly of the icosahedral archaeal viruses closely follows the mechanisms employed by evolutionarily related bacterial and eukaryotic viruses with the HK97 fold and double jelly-roll major capsid proteins, emphasizing the overall conservation of these pathways over billions of years of evolution. By contrast, archaea-specific viruses employ unique virion assembly mechanisms. We also highlight some of the molecular adaptations underlying the stability of archaeal viruses in extreme environments. Despite considerable progress during the past few years, the archaeal virosphere continues to represent one of the least studied parts of the global virome, with many molecular features awaiting to be discovered and characterized.
\end{abstract}

Keywords: viral genome packaging; terminase; FtsK-HerA superfamily ATPase; major capsid protein; HK97 fold; double jelly-roll fold; A-form DNA; extremophiles; hyperthermophilic and halophilic archaea; Sulfolobus 


\section{Introduction: Diversity of archaeal viruses}

Extreme environments, such as hot springs, hydrothermal vents and hypersaline lakes, are dominated by archaeal communities that are associated with a highly diverse virome (Atanasova et al., 2016; Dellas et al., 2014; Krupovic et al., 2018; Luk et al., 2014; Munson-McGee et al., 2018; Prangishvili et al., 2017; Wang et al., 2015). The vast majority of isolated archaeal viruses infect hyperthermophiles and hyperhalophiles of the phyla Crenarchaeaota and Euryarcheaota, respectively. However, several viruses have been recently isolated and described for methanogens (Pfister et al., 1998; Weidenbach et al., 2017; Wolf et al., 2019) and ammonia-oxidizing thaumarchaea (Kim et al., 2019). In addition, putative viruses associated with thaumarchaea (Ahlgren et al., 2019; Chow et al., 2015; Krupovic et al., 2019; Krupovic et al., 2011), marine thermoplasmata (Vik et al., 2017) and marine group II Euryarchaeota (Nishimura et al., 2017; Philosof et al., 2017) were identified using metagenomics, single cell genomics and mining of the archaeal genome sequences for proviruses, suggesting that archaeal viruses play important ecological roles in different ecosystems. Indeed, it has been demonstrated that in the deep ocean, virus-mediated lysis of archaea is more rapid than that of bacteria, with the average abatement rate of $3.2 \%$ per day versus $1.6 \%$ per day, respectively. As a result, turnover of archaea in surface deep-sea sediments accounts for up to one-third of the total microbial biomass killed, resulting in the release of $\sim 0.3$ to 0.5 gigatons of carbon per year globally (Danovaro et al., 2016).

Although all archaeal viruses isolated thus far have DNA genomes, they are extremely diverse in terms of virion morphologies and gene contents. These viruses are currently classified into 20 families (Fig. 1) (Adriaenssens et al., 2020), whereas taxonomic classification of several additional groups remains to be assessed (Geslin et al., 2007; Gorlas et al., 2012; Liu et al., 2019; Mochizuki et al., 2011; Munson-McGee et al., 2020; Wagner et al., 2017; Weidenbach et al., 2017). The archaeal virome encompasses several virus groups that are evolutionarily related to viruses of bacteria and eukaryotes, but most archaeal virus lineages have no counterparts among viruses from the two other domains (Krupovic et al., 2020; Prangishvili et al., 2017). Comparative genomics and bipartite gene-genome network analyses have shown that most of the hyperthermophilic archaeal viruses are disconnected from the rest of the virosphere and likely display distinct evolutionary origins (Iranzo et al., 2016a; Iranzo et al., 2016b).

Perhaps the most iconic virion morphotype exclusive to hyperthermophilic archaea is that of members of the family Ampullaviridae (Prangishvili et al., 2018a) (Figure 1). Virions of ampullaviruses resemble champagne bottles and consist of a nucleoprotein filament condensed into a cone-shaped core, which is encased by an envelope, with the base of the 'bottle' decorated with a ring of 20 filaments (Häring et al., 2005a). Ampullaviruses have been detected in terrestrial hot springs in Italy, Iceland and Japan (Baquero et al., 2020; Gudbergsdóttir et al., 2016; Häring et al., 2005a), but only one representative of this family has been isolated. By contrast, spindle-shaped viruses, which are among the most widespread groups of archaea-specific viruses (Krupovic et al., 2014), are less fastidious and many viruses of this group have been isolated. Tailless spindle-shaped viruses have been isolated from hyperthermophilic crenarchaea (Goodman and Stedman, 2018; Pauly et al., 2019; Redder et al., 2009; Schleper et al., 1992; Stedman, 2011; Wiedenheft et al., 2004; Zhang et al., 2020a), hyperhalophilic euryarchaea (Bath et al., 2006; Bath and Dyall-Smith, 1998) and ammonia-oxidizing thaumarchaea (Kim et al., 2019), and are classified into the families Fuselloviridae, Halspiviridae and Thaspiviridae, respectively (Figure 1). Morphologically similar viruses have been also isolated from hyperthermophilic marine euryarchaea (Geslin et al., 2003; Gorlas et al., 2012), but remain unclassified. Larger spindle-shaped viruses that contain one or two tail-like appendages protruding from the pointed ends of the virion are classified into the family Bicaudaviridae (Prangishvili et al., 2018b; Prangishvili et al., 2006). Another prominent group of archaeal viruses includes filamentous viruses with dsDNA genomes classified into the families Rudiviridae (Prangishvili et al., 1999), Lipothrixviridae, Tristromaviridae (Prangishvili et al., 2019b) and Clavaviridae (Prangishvili et al., 2019a) (Figure 1). Members of the three former families are evolutionarily related and are unified into a proposed class Tokiviricetes (Wang et al., 2020c). Unlike tokiviruses, which have linear dsDNA genomes, clavaviruses have some of the smallest known circular dsDNA genomes (5.2 kb) (Mochizuki et al., 2010). Notably, lipothrixviruses and tristromaviruses are enveloped with a lipid membrane, a feature not observed in filamentous viruses from other domains of life. Other unusual, archaea-specific morphologies include coil-shaped (Spiraviridae) (Mochizuki et al., 2012), peanut-shaped (Ovaliviridae) (Wang et al., 2018), droplet-shaped (Guttaviridae) (Arnold et al., 2000a; Prangishvili et al., 2018d), spherical (Globuloviridae) (Häring et al., 2004; Prangishvili et al., 2018c) and pleomorphic (Pleolipoviridae) (Bamford et al., 2017) virus particles (Figure 1). 
[Insert Figure 1 here]

Similar to bacteria and eukaryotes, archaea are also infected with icosahedral viruses. Tailless icosahedral viruses with an internal membrane layer are classified into the families Turriviridae (Rice et al., 2004), Portogloboviridae (Liu et al., 2017b), Sphaerolipoviridae (Demina et al., 2017) and Simuloviridae (Zhang et al., 2012). The former two families include viruses infecting hyperthermophilic crenarchaea of the genus Sulfolobus/Saccharolobus, whereas the latter two families, until recently, constituted two genera of the same family, Sphaerolipoviridae (Pawlowski et al., 2014), and include evolutionarily related viruses of hyperhalophilic archaea. Finally, archaea host head-tailed viruses, which closely resemble tailed bacteriophages of the order Caudovirales (realm Duplodnaviria). Archaeal head-tailed viruses with all three prototypical tail morphologies have been isolated: long, contractile tails (typical of members of the Myoviridae), short tails (Podoviridae) and long, non-contractile tails (Siphoviridae) (Pietila et al., 2014; Senčilo and Roine, 2014). Notably, most archaeal head-tailed viruses remain unclassified, but following the undergoing reorganization of the order Caudovirales, they are likely to be assigned to multiple new families within the realm Duplodnaviria.

Recent structural studies on archaeal viruses from different families have provided valuable insights into the assembly and organization of their virions as well as on the adaptations to extreme environments in which these viruses thrive. This information, which we summarize in the following sections, has uncovered some unsuspected evolutionary relationships between different families of archaeal viruses and clarified their place in the global virosphere. We note that for many archaeal virus families the information on virion morphogenesis is still lacking.

\section{Assembly of head-tailed archaeal viruses}

Similar to their bacterial relatives, virions of archaeal head-tailed viruses comprise an icosahedral capsid (head) and a helical tail containing tail fibers, which play a role in cell recognition. All head-tailed viruses encapsidate linear dsDNA genomes, which in archaeal viruses can vary in length from $26 \mathrm{~kb}$ to $144 \mathrm{~kb}$. Archaeal head-tailed viruses have been isolated from extreme halophiles (Atanasova et al., 2016) as well as from mesophilic (Pfister et al., 1998; Wolf et al., 2019) and marine hyperthermophilic (Thiroux et al., 2020) methanogens. However, related proviruses have been detected in a wide range of archaea belonging to different phyla, suggesting that the last common archaeal ancestor was already infected with head-tailed viruses (Krupovic et al., 2020).

Comparative genomics analyses have shown that head-tailed archaeal and bacterial viruses as well as eukaryotic herpesviruses share virion morphogenesis modules, including genes encoding proteins involved in capsid assembly, maturation and structure and genome packaging (Dyall-Smith et al., 2020; Krupovic et al., 2010; Senčilo et al., 2013). The structural and computational studies further revealed that these viruses infecting hosts from the three domains of life share homologous major capsid protein (MCPs) with the characteristic HK97-like structural fold, which is not found outside of this virus assemblage (Duda and Teschke, 2019; Krupovic et al., 2010; Krupovic and Koonin, 2017; Pietilä et al., 2013a; Pietilä et al., 2013b). Based on the shared principles of virion assembly and maturation as well as the conserved structure of the capsid proteins, it was hypothesized that head-tailed prokaryotic viruses and eukaryotic herpesviruses have evolved from a common ancestor, which likely preyed on the last universal cellular ancestor (LUCA) (Bamford et al., 2005a; Krupovic et al., 2020; Prangishvili et al., 2017). Recently, all these viruses have been unified by the International Committee on Taxonomy of Viruses (ICTV) within the realm Duplodnaviria (Koonin et al., 2020).

Virion morphogenesis has not been specifically investigated for any of the head-tailed archaeal viruses. However, given that all major components involved in virion morphogenesis are conserved between bacterial and archaeal head-tailed viruses (Fig. 2A), it is likely that the general principles of virion assembly in both virus groups are also the same (Fig. 2B). Below we outline what is known about the assembly of tailed bacteriophages and relate this information to archaeal viruses based on the conservation of the corresponding components and available experimental data.

[Insert Figure 2 here] 


\section{Procapsid assembly}

Similar to tailed bacteriophages and herpesviruses, capsid assembly of head-tailed archaeal viruses is also likely to commence with the formation of an empty procapsid (Fig. 2B). Such empty procapsids have been observed inside the cells infected with Haloarcula vallismortis tailed virus 1 (HVTV-1) (Pietilä et al., 2013a). The procapsid assembly requires the presence of a portal, scaffolding and capsid proteins. The portal protein forms a dodecameric ring, which nucleates the capsid assembly and is located at one of the 12 five-fold vertices of the icosahedral capsid. The portal, as the name implies, also serves as a conduit through which the viral DNA is packaged into and released from the capsid during virus entry (Dedeo et al., 2019; Newcomb et al., 2005; Tavares, 2018). Correct and efficient capsid assembly typically requires the presence of a scaffolding protein, which can be encoded as a standalone protein or as a fusion with the maturation protease or the MCP; the scaffolding protein/domain is subsequently cleaved by the maturation protease and the fragments are removed from the capsid (Dokland, 1999). In archaeal viruses Haloarcula sinaiiensis tailed virus 1 (HSTV-1) and HVTV-1, the N-terminal region of around 100 residues of the MCP have been shown to be proteolytically cleaved in the mature virions (Pietilä et al., 2013a; Pietilä et al., 2013b), resembling the scaffolding domains found in some bacterial viruses, such as HK97 and T5, where the scaffolding domains are fused to the N-terminus of the MCP and undergo proteolysis during capsid maturation (Hendrix, 2005; Huet et al., 2010). By contrast, in Haloferax tailed virus 1 (HFTV1), the scaffolding domain is likely to be fused to the C-terminal region of the prohead protease (Fig. 2A) (Mizuno et al., 2019), resembling the arrangement found in the gpO protein of bacteriophage P2 (Chang et al., 2009).

\section{Capsid maturation}

The scaffolding proteins are proteolytically cleaved by the virus-encoded protease during or prior to genome packaging in both tailed bacteriophages and herpesviruses. This process involves a large structural rearrangement of the procapsid and results in an angular and more stable mature capsid (Dokland, 1999; Steven et al., 2005). The prohead protease was identified in all head-tailed archaeal viruses, indicating a similar capsid maturation process. The cryo-electron microscopy (cryo-EM) 3D reconstruction of the HSTV-1 mature virions has revealed that the capsid is built on the T=7 lattice, with the MCPs arranged into flat hexamers and angular pentamers, similar to the canonical virion architecture of bacteriophage HK97 (Pietilä et al., 2013b; Wikoff et al., 2000). Reconstruction of the HSTV-2 capsid revealed an additional trimeric stabilizing protein inserted directly within the capsid lattice between the hexamers as well as between hexamers and pentamers (Pietilä et al., 2013a). The stabilizing proteins in HSTV-2 occupy the same positions as the trimers of the decoration protein gpD of phage lambda, which provides mechanical stability to the mature capsids (Lander et al., 2008; Pietilä et al., 2013a). Notably, a homolog of the gpD, the triplex protein, also has been identified in the herpesvirus capsids, where, similar to HSTV-2, the protein is inserted into the capsid lattice (Dai and Zhou, 2018). Among structurally characterized head-tailed viruses with $\mathrm{T}=7$ capsids, HSTV-2 has the largest genome, thus it was proposed that the virus likely enlarges the capsid (and internal volume) by incorporating an additional protein into the lattice (Pietilä et al., 2013a). The same function for the triplex protein has been proposed in herpesviruses (Dai and Zhou, 2018). In contrast, HVTV-1 assembles the capsomers on the $\mathrm{T}=13$ lattice (Pietilä et al., 2013a), similar to bacteriophage T5 (Huet et al., 2019). A small trimeric decoration protein was found in the center of the hexameric capsomers in HVTV-1 (Pietilä et al., 2013a), a position similar to that of protein gp12 in bacteriophage SPP1, which has been shown to stabilize the capsid (White et al., 2012), suggesting a similar role for the decoration protein of HVTV1.

\section{Genome packaging}

In tailed bacteriophages and herpesviruses, packaging of the viral dsDNA genomes into preformed procapsids is invariably mediated by the terminase complex, which consists of the large (TerL) and small (TerS) subunits. TerS is a small DNA-binding protein responsible for specific recognition of viral DNA, initiation of the packaging and modulation of the TerL activity (Oliveira et al., 2013; Rao and Feiss, 2015). The TerL subunit consists of two domains and functions as a packaging ATPase that translocates the viral DNA through the portal into the capsid, and as a nuclease that cuts the concatameric viral genome into discrete units (Rao and Feiss, 2015). The terL gene is conserved in all head-tailed archaeal viruses, whereas terS with significant similarity to phage homologs could be identified only in some viruses (e.g., HFTV1, BJ1, phiCh1, phiH1, ChaoS9 and psiM2), likely due to the generally low sequence conservation of the TerS proteins. However, in almost all archaeal viruses that seemingly lack ter $S$, a gene encoding a protein with 
the helix-turn-helix domain that is typical of TerS, could be identified upstream of the terL (unpublished data), suggesting that the complete terminase complex is conserved in all archaeal head-tailed viruses.

Tailed bacteriophages employ a variety of genome packaging mechanisms, which are reflected by the diversity of the genomic termini, including cohesive ends, circularly permuted direct terminal repeats, short or long exact direct terminal repeats, terminal host DNA sequences, or covalently bound terminal proteins (Casjens and Gilcrease, 2009; Garneau et al., 2017). Analysis of the genomic termini has shown that in some archaeal viruses (e.g., HF1, HSTV-2, HVTV-1, etc.), the packaging machinery cleaves the viral genomes at fixed positions, thereby generating direct terminal repeats (Senčilo et al., 2013; Tang et al., 2004), as in the case of bacteriophage T7 (Casjens and Gilcrease, 2009). By contrast other archaeal viruses (e.g., HSTV-1, HFTV1, psiM2, etc.) employ bacteriophage P1-like headful packaging mechanism, whereby the terminase initiates packaging at a specific packaging ( $p a c$ ) site but subsequently cuts the genome at variable positions as soon as the head is full, producing circularly permuted genomes (Mizuno et al., 2019; Pfister et al., 1998; Senčilo et al., 2013).

\section{Tail assembly}

In tailed bacteriophages, upon completion of the genome packaging, the terminase complex is replaced with the neck protein (head-tail connector) (Orlova et al., 2003), followed by the attachment of the preassembled helical tail. The details of tail assembly in archaeal viruses remain enigmatic. Nevertheless, the conserved organizations of the tail morphogenesis modules shared between archaeal and bacterial viruses suggests a common principle of tail assembly. The conservation is especially prominent for archaeal myoviruses, for most of which a nearly complete set of tail morphogenesis genes could be identified. As shown in Figure 2A for the example of myovirus HSTV-2 (revised unpublished annotation), the tail module encompasses the tail terminator, tail sheath, tail tube (major tail protein), two tail assembly proteins, tape measure protein as well as baseplate components, including the hub-like protein, central spike proteins, wedge protein, J-like protein and tail fiber proteins. Archaeal and bacterial siphoviruses also share the tail module, although fewer tail proteins could be confidently matched between bacterial and archaeal viruses (Figure 2A). Notably, the tail assembly proteins of head-tailed archaeal viruses (homologs of HK97 proteins gpG and gpGT), encoded by two overlapping genes, are likely to be produced through a programmed translational frameshifting at a "slippery sequence", as in tailed bacteriophages (Fig. 2A) (Xu et al., 2004; Xu et al., 2013). For archaeal myoviruses and siphoviruses, the dominant morphotypes among the isolated archaeal head-tailed viruses (Atanasova et al., 2015), the tail assembly is expected to be independent of the head assembly, with the preassembled tail being attached to the packaged mature capsid via the neck protein, as has been described in bacterial viruses (Chaban et al., 2015) (Fig. 2B).

\section{Assembly of tailless icosahedral viruses}

Overall virion organization is the same for viruses from all four families of tailless archaeal viruses: the icosahedral protein capsid covers an internal membrane layer, which encloses the dsDNA genome (Figure 1). However, structural studies have revealed that the structures of the protein capsids are very different in viruses from different families. Based on this feature, the four families can be assigned to one of three groups: (i) viruses with double-jelly roll (DJR) MCPs (Turriviridae); (ii) viruses with two single jelly-roll (SJR) MCPs (Sphaerolipoviridae and Simuloviridae) and (iii) viruses with a single SJR MCP (Portogloboviridae). The same three groups can be recapitulated based on gene content analysis of the corresponding viruses.

\section{Turriviridae family}

The icosahedral shell of the prototype virus of the family Turriviridae, Sulfolobus turreted icosahedral virus (STIV), is built on a pseudo T=31 lattice (Khayat et al., 2005; Rice et al., 2004) (Fig. 3A-B). The MCP of STIV, B345, has the DJR fold (Fig. 3C) and forms trimers with a pseudo-hexagonal symmetry, where each subunit has two vertically oriented jelly-rolls (Fig. 3D) (Veesler et al., 2013). The five-fold vertices of the capsid are occupied by a pentamer of the minor capsid (penton) protein A233, which has the SJR fold (Veesler et al., 2013). Very similar virion organization with DJR MCP and SJR pentons is conserved in a wide range of bacterial (e.g., Tectiviridae, Corticoviridae and Finnlakeviridae) and eukaryotic viruses (e.g., Adenoviridae, Lavidaviridae, Phycodnaviridae, Mimiviridae, Asfarviridae, etc.) (Krupovic and Koonin, 
2017). In recognition of the common ancestry, all viruses encoding DJR MCPs, including Turriviridae, were recently unified by the ICTV into the kingdom Bamfordvirae (Koonin et al., 2020).

\section{[Insert Figure 3 here]}

In STIV, each penton base is further decorated by a turret-like appendage that protrudes above the capsid surface (Khayat et al., 2005). Notably, the turrets are also built from a succession of fused SJR motifs with common topologies and similar folds, suggesting that the entire vertex complex has evolved from a simple SJR ancestor through duplication and sequence diversification (Veesler et al., 2013). The turret complex participates in host recognition through binding to pili-like appendages on the host cell surface (Hartman et al., 2019). Notably, each MCP subunit interacts with the inner viral membrane via a C-terminal $\alpha$-helix exhibiting a positive electrostatic potential, which presumably favors interactions with the negatively charged lipid groups of the internal membrane. This interaction is reminiscent of that reported for the Nterminal $\alpha$-helix of the bacterial tectivirus PRD1 MCP (Cockburn et al., 2004; Veesler et al., 2013). STIV morphogenesis shares several other similarities with the assembly pathway of PRD1, reinforcing the evolutionary connection between Turriviridae and other viruses in the kingdom Bamfordvirae. In particular, virion assembly of STIV proceeds through an intermediate stage, whereby prior to genome-packaging, the external icosahedral capsid shell and the inner membrane are tightly coupled, forming empty procapsids, as seen in the case of PRD1 (Fig. 3E) (Fu et al., 2010; Strömsten et al., 2005). It has been suggested that the vertex complexes play a key role in mediating the interactions between the external protein capsid and the membrane. According to this model, the association between the membrane proteins (STIV A55) and the penton base protein (STIV A223) lead to the growth of the capsid shell by the gradual addition of monomeric MCP units in parallel with the formation of the internal membrane (Veesler et al., 2013).

Once the empty procapsids are formed, the dsDNA genome of the virus has to be packaged. Similar to most other members of the Bamfordvirae, STIV encodes the ATPase, B204, of the FtsK-HerA superfamily, homologous to the experimentally characterized genome packaging ATPase of bacterial tectiviruses, but unrelated to the terminases of head-tailed viruses and herpesviruses. In a close relative of STIV, STIV2 (Happonen et al., 2010), the DNA-binding protein B72, an ortholog of the STIV protein A78 (Ortmann et al., 2008) and homologous to the DNA-binding protein VP2 of fuselloviruses (Reiter et al., 1987), has been suggested to serve a critical role in the recruitment of the viral genome to a unique portal complex anchored in the inner membrane of the procapsid (Fig. 3E) (Happonen et al., 2014; Happonen et al., 2013). The portal complex includes the functional ATPase that forms a hexameric ring and uses the hydrolysis of ATP to power the translocation of the viral DNA (Fig. 3E). Biochemical analysis together with the presence of B204 in purified mature virions, reinforce the fundamental role of this protein in viral DNA packaging and virion assembly (Dellas et al., 2015; Happonen et al., 2013). Notably, B204 assembles at a unique genomepackaging vertex suggesting that the genome packaging occurs specifically at one of the 12 five-fold vertices (Fu et al., 2010; Happonen et al., 2014), as in the case of PRD1 (Hong et al., 2014; Stromsten et al., 2003). Notably, however, unlike in PRD1, the genome of turriviruses is circular, raising questions regarding the mechanism of its packaging. Thus, it has been proposed that STIV genome is packaged as a linear molecule and is only subsequently circularized within the capsid through a so far unknown mechanism (Fig. 3E) (Happonen et al., 2014; Happonen et al., 2013).

Small viral membrane proteins have been suggested to form a pore in the internal membrane of the virion at the unique vertex to allow the translocation of the viral genome (Khayat et al., 2010). Upon genome packaging, the capsid does not undergo large conformational changes as described for tailed bacteriophages. Rather, the virion is likely stabilized by the interactions between the inner membrane and the viral genome (Happonen et al., 2013). The mechanism underlying the incorporation of the inner membrane into the virion remains enigmatic. Because partially assembled particles were not detected budding from the cytoplasmatic membrane and based on the fact that viral and cellular membranes have different lipid compositions (Maaty et al., 2006), it has been proposed that the inner viral membrane is formed de novo (Dellas et al., 2015; Fu and Johnson, 2012; Fu et al., 2010). Notably, this process might be facilitated by the cellular Endosomal Sorting Complex Required for Transport (ESCRT) machinery, because perturbation of normal ESCRT function abrogates viral replication (Snyder et al., 2013). Finally, once the mature STIV virions are assembled, they are organized in quasi-crystalline arrays in the host cytoplasm until their release through a lytic mechanism mediated by virus-associated pyramids (Brumfield et al., 2009; Fu et al., 2010). 
STIV and STIV2, both infecting acidophilic hyperthermophiles of the genus Sulfolobus/Saccharolobus, are the only isolated members of the Turriviridae family. However, proviruses encoding MCPs and genome packaging ATPases homologous to those of turriviruses have been identified in a wide range of archaea, including neutrophilic marine and terrestrial hyperthermophiles (Gaudin et al., 2014; Krupovic and Bamford, 2008a; Rensen et al., 2015), methanogens (Krupovic and Bamford, 2008a) and thaumarchaea (Krupovic et al., 2019) as well as several phyla of uncultivated archaea, including Asgard archaea (Krupovic et al., 2020; Yutin et al., 2018). Accordingly, it has been suggested that, as in the case of headtailed viruses, the ancestor of viruses with DJR MCP already existed at the time of LUCA and its descendants were associated with Archaea, ever since their diversification from the common ancestor with Bacteria (Krupovic et al., 2020).

\section{Sphaerolipoviridae family}

Until recently, family Spaherolipoviridae included three genera, Alphasphaerolipovirus, Betasphaerolipovirus and Gammasphaerolipovirus (Pawlowski et al., 2014). Members of the Alphasphaerolipovirus and Betasphaerolipovirus genera infect halophilic archaea and have linear and circular dsDNA genomes, respectively. By contrast, gammasphaerolipoviruses infect thermophilic bacteria (genus Thermus) and encapsidate circular dsDNA genomes (Jaatinen et al., 2008). Viruses from the three genera share overall architecture of the capsid, built using two SJR MCPs, which are oriented vertically with respect to the capsid surface, closely resembling the DJR MCPs of viruses in the Bamfordvirae (GilCarton et al., 2015; Rissanen et al., 2013; Zhang et al., 2012). However, in terms of gene content and sequence similarity, viruses from the three genera share very little (Aiewsakun et al., 2018). Accordingly, it was recently proposed to move genera Betasphaerolipovirus and Gammasphaerolipovirus into separate families, Simuloviridae and Matsushitaviridae, respectively.

Sphaerolipoviridae currently includes four members, three of which, Haloarcula californiae icosahedral virus 1, Haloarcula hispanica icosahedral virus 2 and Haloarcula virus SH1, have been structurally characterized by cryo-EM (De Colibus et al., 2019; Gil-Carton et al., 2015; Santos-Pérez et al., 2019). The icosahedral capsids of these viruses have a $\mathrm{T}=28$ lattice and are built from two MCPs, VP4 and VP7, and a penton protein (VP9), which also has the SJR fold and is located at the five-fold vertices (Fig. 4A-C). VP4 is topped by a further small $\beta$-barrel, which forms a 'tower' protruding away from the capsid surface (Santos-Pérez et al., 2019). The asymmetric unit is composed of one copy of the penton protein, 12 copies of VP4 and 15 copies of VP7 arranged into pseudo-hexagonal three-tower and two-tower capsomers (Fig. 4D). The three-tower capsomers are composed of three alternating VP7-VP4 heterodimers, whereas the two-tower capsomers consist of two VP7-VP4 heterodimers separated by two VP7 monomers (SantosPérez et al., 2019) (Fig. 4D). The five-fold vertices are decorated by impressive horn-like (in Haloarcula virus SH1 and Haloarcula californiae icosahedral virus 1) or propeller-like (in Haloarcula hispanica icosahedral virus 2) spikes. The former are assembled from repeated globular domains attached to a central spine and, presumably, facilitate multimeric attachment to the unidentified cell receptor (De Colibus et al., 2019; Santos-Pérez et al., 2019).

\section{[Insert Figure 4 here]}

The near-atomic resolution structures of sphaerolipoviruses have provided valuable insights into the assembly of their complex capsids. It has been suggested that the building of the capsid lattice primarily relies on proteins located underneath the capsomers, which drive the positioning of the MCP heterodimers and the pentons. In particular, the homopentamers of transmembrane protein VP13, which form a lefthanded coiled-coil, were suggested to act as docking points for the penton complexes, which themselves interact with the membrane through the $\mathrm{N}$-terminal $\alpha$-helices. The pentons, in turn, would nucleate the attachment of VP7-VP4 heterodimers, but the major role in the assembly of VP7-VP4 heterodimers into the two distinct three-tower and two-tower capsomers is attributed to the two membrane-proximal GlobalPositioning-System (GPS) proteins, GPS-II and GPS-III. These proteins are located underneath the threetower and two-tower capsomer bases, suggesting that the localization, fold and oligomerization state of the GPS proteins guides the formation and positioning of the pseudo-hexagonal capsomers on the inner membrane of the virion (Santos-Pérez et al., 2019). In addition, protrusions of VP4 bearing a hydrophobic tip extend from the perimeter of the hetero-hexamers, where they fit into a corresponding pocket formed between the subunits of the adjacent hetero-hexamers, stabilizing the whole assembly. These specific 
hydrophobic contacts were also proposed to play an important role in dictating correct capsid assembly (De Colibus et al., 2019).

Similar to turriviruses, assembly of the sphaerolipovirus virions is thought to proceed through an empty procapsid intermediate. Indeed, empty procapsids have been observed by cryo-EM in virus preparations (Santos-Pérez et al., 2019) as well as inside of the infected cells (Porter et al., 2005). Notably, the internal membrane in procapsids was unexpanded and had a $15 \%$ smaller diameter compared to that in mature virions, similar to what has been previously reported for tectivirus PRD1 (San Martín et al., 2002; SantosPérez et al., 2019). Consistently, sphaerolipoviruses encode putative genome packaging ATPase of the FtsK-HerA superfamily, which is homologous to those encoded by turriviruses and most other viruses with DJR MCPs (Strömsten et al., 2005). Given that sphaerolipoviruses have linear dsDNA genomes with terminal inverted repeats and covalently attached terminal proteins (Porter and Dyall-Smith, 2008), like tectiviruses, it has been proposed that genome packaging occurs by a mechanism similar to that in PRD1 (Bamford et al., 2005b).

As mentioned above, the VP7-VP4 dimer closely corresponds to the DJR MCP structure (De Colibus et al., 2019; Gil-Carton et al., 2015; Santos-Pérez et al., 2019). Thus, it was suggested that viruses with the two SJR MCPs are ancestral to the DJR MCP-encoding viruses, reflecting the state preceding the fusion of two SJR domains into a single DJR MCP (De Colibus et al., 2019; Gil-Carton et al., 2015; Krupovic and Bamford, 2008b). Consequently, viruses with DJR MCPs and two SJR MCPs are unified by the ICTV within the realm Varidnaviria (Koonin et al., 2020).

\section{Portogloboviridae family}

The Portogloboviridae family currently includes two closely related viruses, Sulfolobus polyhedral virus 1 (SPV1) and SPV2 (Liu et al., 2019), although only SPV1 has been isolated as a pure strain (Liu et al., 2017b). SPV1 is unique among bacterial and archaeal icosahedral viruses in that instead of encapsidating a naked dsDNA molecule, its circular genome is condensed and packed in the form a unique spherical nucleoprotein coil. The latter is surrounded by an internal lipid membrane and an outer icosahedral protein shell (Fig. 5A-B) (Wang et al., 2019b). A near-atomic resolution structure of SPV1 virion showed that, unlike in turriviruses and sphaerolipoviruses, the icosahedral capsid is built from a single SJR MCP, VP4 (Fig. 5C), which forms hexameric capsomers (Fig. 5D). The five-fold vertices are occupied by the penton protein VP10, which also has the SJR fold and forms pentamers. Together, VP4 hexamers and VP10 pentamers assemble into an icosahedral shell with a $\mathrm{T}=43$ lattice, not previously described in other viruses (Wang et al., 2019b). Spike complex, presumably involved in host recognition (Fig. 5B), further tops the pentons at the five-fold vertices, with $\alpha$-helices extending from the spike complex plugging the central cavity of the VP10 pentamer. This interaction suggests a possible role of the penton base as a platform for the spikes, as is the case of turriviruses and sphaerolipoviruses (see above). Interestingly, the MCP of SPV1 is homologous to the MCP of the unclassified Metallosphaera turreted icosahedral virus (MTIV) (Wagner et al., 2017). The two MCPs share $27 \%$ sequence identity and VP4 of SPV1 is retrieved as the closest homolog of the MTIV MCP in profile-profile comparisons with the probability of $95.9 \%$ (unpublished observation). This finding suggests that the two viruses have evolved from a common ancestor. However, MTIV genome is half the length of SPV1 $(9.8 \mathrm{~kb}$ versus $20 \mathrm{~kb})$ and is linear with terminal inverted repeats, rather than circular, further highlighting that genomic organizations and replication mechanisms are often disconnected from the capsid architectures in evolutionarily related viruses.

\section{[Insert Figure 5 here]}

Analysis of the composition of the internal membrane of SPV1 showed that lipids are selectively acquired from the host cell (Wang et al., 2019b), as is the case for members of the Lipothrixviridae, Turriviridae and Fuselloviridae families (Kasson et al., 2017; Liu et al., 2017b; Maaty et al., 2006; Quemin et al., 2015), indicating that this strategy could be a common mechanism among crenarchaeal viruses. The internal membrane of SPV1 displays an icosahedral shape, presumably due to the presence of an intricate array of subcapsomer proteins that spans the space between the membrane and the external icosahedral shell (Wang et al., 2019b), as seen in bacterial tectiviruses (Cockburn et al., 2004; Laurinmäki et al., 2005). Virion proteins VP3, VP5, VP6, and VP7 have transmembrane helices and are the presumed constituents of this array. Notably, the array is symmetrically organized around the five-fold vertices and makes contacts with each VP4 hexamer, likely playing a key role in correct positioning of the hexamers during capsid assembly. 
By contrast, unlike in turriviruses and sphaerolipoviruses, the penton base does not appear to be connected to the membrane.

Perhaps the most intriguing part of the SPV1 reconstruction is the unique nucleoprotein core (Wang et al., 2019b). Dissociation experiments have implicated the $\alpha$-helical protein VP1 as the main constituent of the nucleoprotein filament (Liu et al., 2017b). Consistently, in vitro assays have confirmed the DNA binding activity of VP1. The reconstruction of the nucleoprotein core revealed that VP1 dimers cover the circular dsDNA genome of the virus. Interestingly, the reconstructed model for the nucleoprotein filament suggested that SPV1 DNA is stored in A-form conformation, with $11 \mathrm{bp} /$ turn and a rise of $2.6 \AA / \mathrm{bp}$, similar to what has been described for hyperthermophilic archaeal viruses of the class Tokiviricetes (see below). Partial dissociation of the nucleoprotein core revealed the presence of four types of filaments: naked dsDNA, single nucleoprotein filaments, supercoiling bundles of nucleoprotein filaments and rafts in which the filaments are connected to each other by loops (Wang et al., 2019b). These observations prompted a model for the packaging of the SPV1 genome, whereby the circular nucleoprotein (dsDNA-VP1) is first folded as a long double filament, which is then folded into a raft and spooled into a 'ball' (Fig. 5E). How the spherical nucleoprotein core is enveloped with a lipid membrane and subsequently covered with an icosahedral capsid remains unknown.

A visually similar organization of the nucleoprotein core has been described for Sulfolobus ellipsoid virus 1 (SEV1), the sole member of the Ovaliviridae family (Wang et al., 2018). However, unlike SPV1, SEV1 does not contain an external icosahedral capsid. Instead, the virions are ellipsoid, with the nucleoprotein coil being surrounded by a lipid membrane (Wang et al., 2018). SEV1 virions display helical striations aligned perpendicularly to the longitudinal axis of the particle, resembling those observed for SPV1 (Liu et al., 2017b; Wang et al., 2019b). This observation, along with the three-dimensional electron tomography of the virion, prompted a model for the organization of the SEV1 nucleocapsid, whereby the viral DNA wraps around the longitudinal axis of the virion to form stacks of flat disk-like structures with a central cavity (Wang et al., 2018). Accordingly, sixteen disk-like structures, which are evenly distributed in the virion, stack together to form a spool-like capsid that is covered by a lipid envelope decorated with protruding spikes (Wang et al., 2018). Given its high abundance in the virion, it has been suggested that protein VP4 is involved in the formation of the nucleoprotein filament, whereas transmembrane domains-containing proteins VP1 and VP2 are associated with the viral envelope. Notably, nucleoproteins of SPV1 and SEV1 do not display any appreciable sequence similarity. Interestingly, electron micrographs of infected cells showed enveloped viral capsids in the cytoplasm of the host cell, indicating that the virus acquires the lipid membrane intracellularly by an unknown mechanism (Wang et al., 2018).

\section{Assembly of filamentous viruses}

Filamentous archaeal viruses for which structures have been elucidated at near-atomic resolution belong to the Clavaviridae, Rudiviridae, Lipothrixviridae and Tristromaviridae families, all infecting hyperthermophilic hosts of the phylum Crenarchaeota. Cryo-EM reconstructions have revealed unexpected similarities in the structural organization of viruses from the latter three families, despite the lack of significant sequence similarity among the corresponding viral genomes. By contrast, clavaviruses display a unique virion organization, not observed in any other characterized virus.

\section{Clavaviridae family}

The sole known member of the Clavaviridae family, Aeropyrum pernix bacilliform virus 1 (APBV1), forms non-enveloped, rigid, bacilliform virions with two terminal cap structures at either end - one pointed and the other rounded (Mochizuki et al., 2010). The virions are built from a single, highly glycosylated MCP and three minor structural proteins. The MCP has one of the simplest known structural folds consisting of two long kinked $\alpha$-helices connected by a $\beta$-hairpin, while all three minor capsid proteins have likely evolved through duplication and sequence diversification of the APBV1 MCP (Ptchelkine et al., 2017). The MCP forms the helical tube, while the minor capsid proteins are believed to participate in the assembly of the cap structure. Most amino acid side-chains in both $\alpha$-helices of the MCP are hydrophobic, with only the inner and outer ends of the subunits containing polar and charged residues. Each MCP subunit makes extensive hydrophobic contacts to six other neighboring MCP subunits, eventually assembling a tubular structure with a hydrophobic core inside the wall of the capsid. By contrast, the inner surface of the tube is positively charged, which presumably allows interactions with the viral genome and its packaging as a left- 
handed superhelix. A model for the assembly of APBV1 has been proposed in which the virion assembly starts when one of the two cap structures recognizes and binds to the viral genome at three specific sites, forming three long loops. These gradually intertwine under the guidance of the concomitant capsid assembly to form a left-handed superhelix. Finally, once the DNA is fully covered with the MCP, the open end of the virion is sealed by the second cap structure (Ptchelkine et al., 2017).

\section{Rudiviridae family}

Members of the Rudiviridae have non-enveloped rod-shaped virions formed by condensation of the linear dsDNA by multiple copies of a homodimer of the MCP (Fig. 6A-D) (DiMaio et al., 2015). Both ends of the virion are decorated with terminal fibers (Fig. 6A), which play a crucial role in the host recognition and binding via highly glycosylated type 4 pili (Quemin et al., 2013; Rowland et al., 2020; Wang et al., 2020b; Wang et al., 2019a). Nuclear magnetic resonance analysis has shown that in solution, the C-terminal half of the MCP folds into a compact four-helix bundle, while the N-terminal half is unstructured (Szymczyna et al., 2009). However, in the virion, upon binding to the DNA genome, the $\mathrm{N}$-terminal unstructured region folds into a single extended helix that tightly wraps around the DNA. Cryo-EM reconstructions of Sulfolobus rod-shaped virus 2 and Saccharolobus solfataricus rod-shaped virus 1 revealed that MCP homodimers make extensive electrostatic interactions with the phosphate backbone of the dsDNA (DiMaio et al., 2015; Wang et al., 2020a), effectively dehydrating it and transforming the physiologically common B-form DNA into A-form conformation (Fig. 6C-D). The hydrophobic protein-protein interactions across the helical turns form a solvent-inaccessible surface that surrounds the DNA and protects it from the acidic environment in which these viruses reside (DiMaio et al., 2015).

\section{[Insert Figure 6 here]}

\section{Lipothrixviridae family}

Members of the Lipothrixviridae family infect hyperthermophilic acidophiles of the order Sulfolobales and have filamentous virions that are decorated at each end with diverse terminal structures that can resemble claws (Acidianus filamentous virus 1 [AFV1]), brushes (AFV2) or mops (Sulfolobus islandicus filamentous virus [SIFV]) and are likely to be involved in the virus attachment to the host cell (Arnold et al., 2000b; Bettstetter et al., 2003; Häring et al., 2005b) (Fig. 6D). High-resolution structures are available for three members of the Lipothrixviridae, namely, AFV1 (Kasson et al., 2017), Sulfolobus filamentous virus 1 (SFV1) (Liu et al., 2018) and SIFV (Wang et al., 2020a). Lipothrixviruses share extensive gene content with rudiviruses and, accordingly, the two families were grouped into the order Ligamenvirales (Prangishvili and Krupovic, 2012). However, unlike rudiviruses, lipothrixviruses are enveloped with a lipid membrane, whereas the nucleocapsid is built from heterodimers of two homologous MCPs (Fig. 6E-F) that closely resemble the symmetrical homodimer of rudiviruses (Fig. 6C). Importantly, as in rudiviruses, the lipothrixvirus genomes are also stored in the virions as A-form DNA. The mechanism of lipothrixvirus nucleocapsid assembly is thus likely to be very similar to the assembly of rudivirus capsids (Fig. 6M), with multiple copies of the MCP heterodimer binding to the linear dsDNA and transforming it into A-form (Fig. $6 \mathrm{H})$. Notably, lipothrixviruses display considerable variation in the properties of the superhelical nucleocapsid, including the diameter, flexibility and surface electrostatic potential. Furthermore, one of the two MCPs of SFV1 and SIFV, but not AFV1, contain C-terminal hook-like extensions that make contacts across the helical groove of the nucleocapsid, stapling the nucleocapsid and thereby probably stabilizing it (Liu et al., 2018; Wang et al., 2020a).

A remarkable feature of lipothrixvirus virions is their membranes, which are half as thin as the cytoplasmic membrane of the host (Kasson et al., 2017; Liu et al., 2018; Wang et al., 2020a). Lipid analysis has shown that AFV1 specifically selects for a flexible glycerol dibiphytanyl glycerol tetraether lipid lacking cyclopentane rings (GDGT-0), which can be bent into a U-shaped 'horseshoe' conformation. Molecular dynamics simulation has shown that such thin lipid envelope containing horseshoe GDGT-0 lipids would be stable and have the necessary curvature to surround the nucleocapsid (Kasson et al., 2017). The horseshoe lipid conformation has been observed in vitro at the air-water interface, but never before in a biological system (Kohler et al., 2006). By contrast, the thin SFV1 membrane is strongly enriched in archaeol ( $~ 80 \%$ of all lipids), a short lipid molecule that is half as long as GDGT tetraethers and present at $\sim 1 \%$ in the host membrane. Thus, the thickness of the SFV1 membrane is consistent with the monolayer composed of archaeol (Liu et al., 2018). Consequently, lipothrixviruses have evolved different routes to converge on thin 
lipid membranes. However, the function of the viral envelope as well as the actual mechanism of envelopment and lipid selection remain to be studied in detail.

\section{Tristromaviridae family}

Viruses belonging to the Tristromaviridae family infect neutrophilic hyperthermophiles of the order Thermoproteales and have slightly flexible filamentous virions with terminal filaments attached to one or both ends (Baquero et al., 2020; Rensen et al., 2016; Wang et al., 2020c) and responsible for host recognition by binding to type 4 pili (Wang et al., 2020b). Although initially thought to be evolutionarily unrelated to other known viruses due to lack of any identifiable sequence similarity (Rensen et al., 2016), the cryo-EM structure of the Pyrobaculum filamentous virus 2 has uncovered an unexpected relationship with rudiviruses and lipothrixviruses (Wang et al., 2020c). The nucleocapsid core of tristromaviruses turns out to be built using the same general principle as in lipothrixviruses, from heterodimers with the same $\alpha$ helical fold (Fig. 6I-K). The linear dsDNA genome is also condensed and maintained in an A-form conformation (Fig. 6J-L) (Wang et al., 2020c). The fact that A-form DNA is found in two evolutionarily unrelated lineages of hyperthermophilic viruses (i.e., with filamentous and icosahedral virions) infecting both neutrophilic (Thermoproteales) and acidophilic (Sulfolobales) hosts suggests that A-form DNA is a general adaptation of crenarchaeal viruses to extreme temperatures rather than low $\mathrm{pH}$ (Wang et al., 2020c). Notably, unlike in lipothrixviruses, the envelope of tristromaviruses has the same thickness and lipid composition as the host membrane (Rensen et al., 2016), emphasizing the variety of mechanisms employed by filamentous enveloped viruses for lipid selection.

\section{Assembly of spindle-shaped viruses}

Spindle-shaped viruses are widespread in archaea-dominated environments and represent a prominent component of the archaeal virosphere (Krupovic et al., 2014). However, due to intrinsic flexibility and heterogeneity of the spindle-shaped virions, structural studies on these viruses remain highly challenging (Hong et al., 2015; Stedman et al., 2015). Nevertheless, dual-axis electron tomography analysis has shed light on the morphogenesis and release of the prototypical fusellovirus Sulfolobus spindle-shaped virus 1 (SSV1) (Quemin et al., 2016).

\section{Fuselloviridae family}

Members of the Fuselloviridae family have small lemon-shaped virions decorated with terminal fibers at one of the two pointed ends (Contursi et al., 2014; Stedman et al., 2015). The virions of SSV1 consist of four virus-encoded structural proteins, VP1-VP4 (Quemin et al., 2015), with the circular dsDNA genome being packaged within the virion as a nucleoprotein complex. Mass spectrometry analysis has also revealed the presence of the major host chromatin protein of the Sul7d family in the highly purified SSV1 virions, suggesting its involvement in condensation of the viral DNA (Quemin et al., 2015). In vitro studies have demonstrated that Sul7d proteins bind dsDNA nonspecifically and induce negative supercoiling and compaction of relaxed and positively supercoiled DNA (López-García et al., 1998; Zhang et al., 2020b). Notably, the DNA isolated from SSV1 virions was found to be positively supercoiled by reverse gyrase (Nadal et al., 1986) and can thus be efficiently condensed by the Sul7d proteins. In addition, some fuselloviruses (e.g., SSV1) encode their own DNA-binding protein, VP2, which has also been suggested to participate in the condensation of the viral genome (Reiter et al., 1987). However, deletion of $v p 2$ gene from the SSV1 genome had no effect on the infectivity (Iverson and Stedman, 2012), suggesting that VP2 does not play a major role in genome packing.

The assembly of SSV1 virions is concomitant with its egress at the cellular cytoplasmic membrane by a mechanism that resembles the budding of enveloped eukaryotic viruses (Quemin et al., 2016). Electron tomography analysis has shown that viral nucleoprotein complexes are extruded through the cytoplasmic membrane as rod-shaped intermediate structures that possess an envelope continuous with the host membrane (Fig. 7A). Terminal fibers presumably consisting of the heavily glycosylated protein VP4 and involved in host recognition (Quemin et al., 2015), were found at the tip of the budding virus particles (Quemin et al., 2016), suggesting that VP4 nucleates the virion assembly at the host membrane, which is believed to contain the hydrophobic major and minor glycoproteins, VP1 and VP3, respectively. Notably, prior to virion assembly, VP1 is proteolytically processed by an unidentified protease at a conserved glutamate residue, removing the N-terminal region (Quemin et al., 2015; Reiter et al., 1987). However, the 
gene fragment encoding this region could not be deleted (Iverson et al., 2017b), suggesting that it is important for correct subcellular protein localization and/or virion morphogenesis. Subsequently, the neck of the budding virus particle is constricted at the base, sealing the host membrane and releasing the virion (Fig. 7B). Following the virion detachment from the membrane, further maturation of the elongated particles into the typical spindle-shaped morphology takes place in proximity of the cell surface (Fig. 7C). Notably, SSV1 deletion mutant lacking the $v p 3$ gene had elongated virions, even though the infectivity was not lost, suggesting that VP3 participates in the transition from elongated to spindle-shaped particles (Iverson et al., 2017a). Upon budding, SSV1 virions locally disorganize the S-layer to gain access to the environment (Quemin et al., 2016). Similarly, the morphogenesis and egress of non-lytic viruses, such as globuloviruses and pleolipoviruses, have been suggested to be concomitant and occur at the cellular cytoplasmic membrane through a budding mechanism (Baquero et al., 2020; Demina and Oksanen, 2020).

\section{[Insert Figure 7 here]}

\section{Bicaudaviridae family}

Representatives of the Bicaudaviridae family have tails of different lengths at one or both pointed ends of the lemon-shaped body (Krupovic et al., 2014; Prangishvili et al., 2006). The morphogenesis of Bicaudaviridae virions is also likely to occur at the cell surface and the ESCRT machinery has been proposed to be required for Sulfolobus tengchongensis spindle-shaped virus 2 budding (Liu et al., 2017a). Remarkably, the prototypical virus of the family, Acidianus two-tailed virus (ATV), undergoes a morphological transformation outside and independent of the host cell. ATV virions are released from the host cell as tailless fusiform particles, after which they develop extracellularly long tails at both ends of the spindle-shaped virion at temperatures of the natural habitat, i.e., $85^{\circ} \mathrm{C}$ (Prangishvili et al., 2006). The putative family member Sulfolobus monocaudavirus 1 was also reported to develop tails in extracellular environments, whereas Sulfolobus tengchongensis spindle-shaped viruses 1 and 2 apparently lack this property and have a single tail (Erdmann et al., 2014; Uldahl et al., 2016; Xiang et al., 2005).

A combination of cryo-EM and X-ray crystallography shed light on the structural organization of the Acidianus tailed spindle virus (Hochstein et al., 2018; Hochstein et al., 2016). Bicaudavirus MCP has a unique four-helix bundle fold (Goulet et al., 2010; Hochstein et al., 2015), not found in other viruses or cellular organisms (Krupovic and Koonin, 2017). Based on the packing of the MCP subunits in the crystal, it has been proposed that the capsid of Acidianus tailed spindle virus is formed through a metastable fourstart helical assembly with variable radius that extends through the lemon-shaped body into the tail (Hochstein et al., 2018). Notably, a smooth transition from the spindle-shaped capsid into a tubular tail with no visible boundaries was observed, indicating that the virion structure is continuous throughout the length of the particle. This observation is seemingly supported by the extracellular tail development of ATV, whereby the tail growth is related with the diminution of the volume in the body, suggesting movement of the capsid proteins from the spindle-shaped body to the growing tail (Hochstein et al., 2018; Prangishvili et al., 2006).

\section{Conclusions}

Recent progress in cryo-EM and electron tomography has boosted the studies on the mechanisms of virion assembly and structure of archaeal viruses. These studies have revealed that assembly and genome packaging in filamentous hyperthermophilic viruses occur in a coordinated fashion, whereas the strategy employed by certain head-tailed and tailless icosahedral viruses relies on the formation of empty capsids which are subsequently filled with the DNA genomes in an ATP-dependent manner. Generally, the assembly of the icosahedral archaeal viruses closely follows the mechanisms employed by evolutionarily related bacterial and eukaryotic viruses, emphasizing the overall conservation of these pathways over billions of years of evolution, which have passed since the divergence of the cellular lineages corresponding to the three domains of life. Despite the considerable progress made in understanding the general principles underlying the morphogenesis of head-tailed, tailless icosahedral, filamentous and spindle-shaped virions, the exact molecular details and, especially, the dynamics of these processes are still lacking. At the same time, the remarkable diversity of archaeal viruses should prompt the structural characterization of new model systems to broaden our comprehension of the diversity of molecular solutions evolved by these viruses for survival in extreme environmental conditions. 


\section{Acknowledgments}

This work was supported by l'Agence Nationale de la Recherche Grant ANR-17-CE15-0005-01 (M.K.) and NIH Grant R35GM122510 (E.H.E.). D.P.B. is part of the Pasteur-Paris University International PhD Program, which has received funding from the European Union's Horizon 2020 Research and Innovation Programme under Marie Sklodowska-Curie Grant Agreement 665807. Y.L. is a recipient of the PasteurRoux-Cantarini Fellowship from Institut Pasteur. 


\section{References}

Adriaenssens, E. M., Sullivan, M. B., Knezevic, P., van Zyl, L. J., Sarkar, B. L., Dutilh, B. E., Alfenas-Zerbini, P., Lobocka, M., Tong, Y., Brister, J. R., Moreno Switt, A. I., Klumpp, J., Aziz, R. K., Barylski, J., Uchiyama, J., Edwards, R. A., Kropinski, A. M., Petty, N. K., Clokie, M. R. J., Kushkina, A. I., Morozova, V. V., Duffy, S., Gillis, A., Rumnieks, J., Kurtboke, I., Chanishvili, N., Goodridge, L., Wittmann, J., Lavigne, R., Jang, H. B., Prangishvili, D., Enault, F., Turner, D., Poranen, M. M., Oksanen, H. M., and Krupovic, M. (2020). Taxonomy of prokaryotic viruses: 2018-2019 update from the ICTV Bacterial and Archaeal Viruses Subcommittee. Arch Virol 165, 1253.

Ahlgren, N. A., Fuchsman, C. A., Rocap, G., and Fuhrman, J. A. (2019). Discovery of several novel, widespread, and ecologically distinct marine Thaumarchaeota viruses that encode amoC nitrification genes. ISME J 13, 618.

Aiewsakun, P., Adriaenssens, E. M., Lavigne, R., Kropinski, A. M., and Simmonds, P. (2018). Evaluation of the genomic diversity of viruses infecting bacteria, archaea and eukaryotes using a common bioinformatic platform: steps towards a unified taxonomy. J Gen Virol 99, 1331.

Arnold, H. P., Ziese, U., and Zillig, W. (2000a). SNDV, a novel virus of the extremely thermophilic and acidophilic archaeon Sulfolobus. Virology 272, 409.

Arnold, H. P., Zillig, W., Ziese, U., Holz, I., Crosby, M., Utterback, T., Weidmann, J. F., Kristjanson, J. K., Klenk, H. P., Nelson, K. E., and Fraser, C. M. (2000b). A novel lipothrixvirus, SIFV, of the extremely thermophilic crenarchaeon Sulfolobus. Virology 267, 252.

Atanasova, N. S., Bamford, D. H., and Oksanen, H. M. (2015). Haloarchaeal virus morphotypes. Biochimie $118,333$.

Atanasova, N. S., Bamford, D. H., and Oksanen, H. M. (2016). Virus-host interplay in high salt environments. Environ Microbiol Rep 8, 431.

Bamford, D. H., Grimes, J. M., and Stuart, D. I. (2005a). What does structure tell us about virus evolution? Curr Opin Struct Biol 15, 655.

Bamford, D. H., Pietila, M. K., Roine, E., Atanasova, N. S., Dienstbier, A., Oksanen, H. M., and ICTV Report Consortium. (2017). ICTV Virus Taxonomy Profile: Pleolipoviridae. J Gen Virol 98, 2916.

Bamford, D. H., Ravantti, J. J., Rönnholm, G., Laurinavicius, S., Kukkaro, P., Dyall-Smith, M., Somerharju, P., Kalkkinen, N., and Bamford, J. K. (2005b). Constituents of SH1, a novel lipid-containing virus infecting the halophilic euryarchaeon Haloarcula hispanica. J Virol 79, 9097.

Baquero, D. P., Contursi, P., Piochi, M., Bartolucci, S., Liu, Y., Cvirkaite-Krupovic, V., Prangishvili, D., and Krupovic, M. (2020). New virus isolates from Italian hydrothermal environments underscore the biogeographic pattern in archaeal virus communities. ISME J 14, 1821.

Bath, C., Cukalac, T., Porter, K., and Dyall-Smith, M. L. (2006). His1 and His2 are distantly related, spindleshaped haloviruses belonging to the novel virus group, Salterprovirus. Virology 350, 228.

Bath, C., and Dyall-Smith, M. L. (1998). His1, an archaeal virus of the Fuselloviridae family that infects Haloarcula hispanica. J Virol 72, 9392.

Bettstetter, M., Peng, X., Garrett, R. A., and Prangishvili, D. (2003). AFV1, a novel virus infecting hyperthermophilic archaea of the genus acidianus. Virology 315, 68.

Brumfield, S. K., Ortmann, A. C., Ruigrok, V., Suci, P., Douglas, T., and Young, M. J. (2009). Particle assembly and ultrastructural features associated with replication of the lytic archaeal virus sulfolobus turreted icosahedral virus. J Virol 83, 5964.

Casjens, S. R., and Gilcrease, E. B. (2009). Determining DNA packaging strategy by analysis of the termini of the chromosomes in tailed-bacteriophage virions. Methods Mol Biol 502, 91.

Chaban, Y., Lurz, R., Brasiles, S., Cornilleau, C., Karreman, M., Zinn-Justin, S., Tavares, P., and Orlova, E. V. (2015). Structural rearrangements in the phage head-to-tail interface during assembly and infection. Proc Natl Acad Sci U S A 112, 7009.

Chang, J. R., Spilman, M. S., Rodenburg, C. M., and Dokland, T. (2009). Functional domains of the bacteriophage P2 scaffolding protein: identification of residues involved in assembly and protease activity. Virology 384, 144.

Chow, C. E., Winget, D. M., White, R. A., 3rd, Hallam, S. J., and Suttle, C. A. (2015). Combining genomic sequencing methods to explore viral diversity and reveal potential virus-host interactions. Front Microbiol 6, 265. 
Cockburn, J. J., Abrescia, N. G., Grimes, J. M., Sutton, G. C., Diprose, J. M., Benevides, J. M., Thomas, G. J., Jr., Bamford, J. K., Bamford, D. H., and Stuart, D. I. (2004). Membrane structure and interactions with protein and DNA in bacteriophage PRD1. Nature 432, 122.

Contursi, P., Fusco, S., Cannio, R., and She, Q. (2014). Molecular biology of fuselloviruses and their satellites. Extremophiles 18, 473.

Dai, X., and Zhou, Z. H. (2018). Structure of the herpes simplex virus 1 capsid with associated tegument protein complexes. Science 360 , eaao7298.

Danovaro, R., Dell'Anno, A., Corinaldesi, C., Rastelli, E., Cavicchioli, R., Krupovic, M., Noble, R. T., Nunoura, T., and Prangishvili, D. (2016). Virus-mediated archaeal hecatomb in the deep seafloor. Sci Adv 2, e1600492.

De Colibus, L., Roine, E., Walter, T. S., Ilca, S. L., Wang, X., Wang, N., Roseman, A. M., Bamford, D., Huiskonen, J. T., and Stuart, D. I. (2019). Assembly of complex viruses exemplified by a halophilic euryarchaeal virus. Nat Commun 10, 1456.

Dedeo, C. L., Cingolani, G., and Teschke, C. M. (2019). Portal Protein: The Orchestrator of Capsid Assembly for the dsDNA Tailed Bacteriophages and Herpesviruses. Annu Rev Virol 6, 141.

Dellas, N., Snyder, J. C., Bolduc, B., and Young, M. J. (2014). Archaeal Viruses: Diversity, Replication, and Structure. Annu Rev Virol 1, 399.

Dellas, N., Snyder, J. C., Dills, M., Nicolay, S. J., Kerchner, K. M., Brumfield, S. K., Lawrence, C. M., and Young, M. J. (2015). Structure-Based Mutagenesis of Sulfolobus Turreted Icosahedral Virus B204 Reveals Essential Residues in the Virion-Associated DNA-Packaging ATPase. J Virol 90, 2729.

Demina, T. A., and Oksanen, H. M. (2020). Pleomorphic archaeal viruses: the family Pleolipoviridae is expanding by seven new species. Arch Virol.

Demina, T. A., Pietilä, M. K., Svirskaitè, J., Ravantti, J. J., Atanasova, N. S., Bamford, D. H., and Oksanen, H. M. (2017). HCIV-1 and Other Tailless Icosahedral Internal Membrane-Containing Viruses of the Family Sphaerolipoviridae. Viruses 9, 32.

DiMaio, F., Yu, X., Rensen, E., Krupovic, M., Prangishvili, D., and Egelman, E. H. (2015). Virology. A virus that infects a hyperthermophile encapsidates A-form DNA. Science 348, 914.

Dokland, T. (1999). Scaffolding proteins and their role in viral assembly. Cell Mol Life Sci 56, 580.

Duda, R. L., and Teschke, C. M. (2019). The amazing HK97 fold: versatile results of modest differences. Curr Opin Virol 36, 9.

Dyall-Smith, M., Tang, S. L., Russ, B., Chiang, P. W., and Pfeiffer, F. (2020). Comparative Genomics of Two New HF1-like Haloviruses. Genes (Basel) 11, 405.

Erdmann, S., Chen, B., Huang, X., Deng, L., Liu, C., Shah, S. A., Le Moine Bauer, S., Sobrino, C. L., Wang, H., Wei, Y., She, Q., Garrett, R. A., Huang, L., and Lin, L. (2014). A novel single-tailed fusiform Sulfolobus virus STSV2 infecting model Sulfolobus species. Extremophiles 18, 51.

Fu, C. Y., and Johnson, J. E. (2012). Structure and cell biology of archaeal virus STIV. Curr Opin Virol 2, 122.

Fu, C. Y., Wang, K., Gan, L., Lanman, J., Khayat, R., Young, M. J., Jensen, G. J., Doerschuk, P. C., and Johnson, J. E. (2010). In vivo assembly of an archaeal virus studied with whole-cell electron cryotomography. Structure 18, 1579.

Garneau, J. R., Depardieu, F., Fortier, L. C., Bikard, D., and Monot, M. (2017). PhageTerm: a tool for fast and accurate determination of phage termini and packaging mechanism using next-generation sequencing data. Sci Rep 7, 8292.

Gaudin, M., Krupovic, M., Marguet, E., Gauliard, E., Cvirkaite-Krupovic, V., Le Cam, E., Oberto, J., and Forterre, P. (2014). Extracellular membrane vesicles harbouring viral genomes. Environ Microbiol $16,1167$.

Geslin, C., Gaillard, M., Flament, D., Rouault, K., Le Romancer, M., Prieur, D., and Erauso, G. (2007). Analysis of the first genome of a hyperthermophilic marine virus-like particle, PAV1, isolated from Pyrococcus abyssi. J Bacteriol 189, 4510.

Geslin, C., Le Romancer, M., Erauso, G., Gaillard, M., Perrot, G., and Prieur, D. (2003). PAV1, the first viruslike particle isolated from a hyperthermophilic euryarchaeote, "Pyrococcus abyssi". J Bacteriol $185,3888$.

Gil-Carton, D., Jaakkola, S. T., Charro, D., Peralta, B., Castaño-Díez, D., Oksanen, H. M., Bamford, D. H., and Abrescia, N. G. A. (2015). Insight into the Assembly of Viruses with Vertical Single $\beta$-barrel Major Capsid Proteins. Structure 23, 1866. 
Goodman, D. A., and Stedman, K. M. (2018). Comparative genetic and genomic analysis of the novel fusellovirus Sulfolobus spindle-shaped virus 10. Virus Evol 4, vey022.

Gorlas, A., Koonin, E. V., Bienvenu, N., Prieur, D., and Geslin, C. (2012). TPV1, the first virus isolated from the hyperthermophilic genus Thermococcus. Environ Microbiol 14, 503.

Goulet, A., Vestergaard, G., Felisberto-Rodrigues, C., Campanacci, V., Garrett, R. A., Cambillau, C., and Ortiz-Lombardia, M. (2010). Getting the best out of long-wavelength X-rays: de novo chlorine/sulfur SAD phasing of a structural protein from ATV. Acta Crystallogr D Biol Crystallogr 66, 304.

Gudbergsdóttir, S. R., Menzel, P., Krogh, A., Young, M., and Peng, X. (2016). Novel viral genomes identified from six metagenomes reveal wide distribution of archaeal viruses and high viral diversity in terrestrial hot springs. Environ Microbiol 18, 863.

Happonen, L. J., Erdmann, S., Garrett, R. A., and Butcher, S. J. (2014). Adenosine triphosphatases of thermophilic archaeal double-stranded DNA viruses. Cell Biosci 4, 37.

Happonen, L. J., Oksanen, E., Liljeroos, L., Goldman, A., Kajander, T., and Butcher, S. J. (2013). The structure of the NTPase that powers DNA packaging into Sulfolobus turreted icosahedral virus 2. J Virol 87, 8388.

Happonen, L. J., Redder, P., Peng, X., Reigstad, L. J., Prangishvili, D., and Butcher, S. J. (2010). Familial relationships in hyperthermo- and acidophilic archaeal viruses. J Virol 84, 4747.

Häring, M., Peng, X., Brügger, K., Rachel, R., Stetter, K. O., Garrett, R. A., and Prangishvili, D. (2004). Morphology and genome organization of the virus PSV of the hyperthermophilic archaeal genera Pyrobaculum and Thermoproteus: a novel virus family, the Globuloviridae. Virology 323, 233.

Häring, M., Rachel, R., Peng, X., Garrett, R. A., and Prangishvili, D. (2005a). Viral diversity in hot springs of Pozzuoli, Italy, and characterization of a unique archaeal virus, Acidianus bottle-shaped virus, from a new family, the Ampullaviridae. J Virol 79, 9904.

Häring, M., Vestergaard, G., Brügger, K., Rachel, R., Garrett, R. A., and Prangishvili, D. (2005b). Structure and genome organization of AFV2, a novel archaeal lipothrixvirus with unusual terminal and core structures. J Bacteriol 187, 3855.

Hartman, R., Eilers, B. J., Bollschweiler, D., Munson-McGee, J. H., Engelhardt, H., Young, M. J., and Lawrence, C. M. (2019). The Molecular Mechanism of Cellular Attachment for an Archaeal Virus. Structure 27, 1634.

Hendrix, R. W. (2005). Bacteriophage HK97: assembly of the capsid and evolutionary connections. Adv Virus Res 64, 1.

Hochstein, R., Bollschweiler, D., Dharmavaram, S., Lintner, N. G., Plitzko, J. M., Bruinsma, R., Engelhardt, H., Young, M. J., Klug, W. S., and Lawrence, C. M. (2018). Structural studies of Acidianus tailed spindle virus reveal a structural paradigm used in the assembly of spindle-shaped viruses. Proc Natl Acad Sci U S A 115, 2120.

Hochstein, R., Bollschweiler, D., Engelhardt, H., Lawrence, C. M., and Young, M. (2015). Large Tailed Spindle Viruses of Archaea: a New Way of Doing Viral Business. J Virol 89, 9146.

Hochstein, R. A., Amenabar, M. J., Munson-McGee, J. H., Boyd, E. S., and Young, M. J. (2016). Acidianus Tailed Spindle Virus: a New Archaeal Large Tailed Spindle Virus Discovered by CultureIndependent Methods. J Virol 90, 3458.

Hong, C., Oksanen, H. M., Liu, X., Jakana, J., Bamford, D. H., and Chiu, W. (2014). A structural model of the genome packaging process in a membrane-containing double stranded DNA virus. PLoS Biol 12, e1002024.

Hong, C., Pietilä, M. K., Fu, C. J., Schmid, M. F., Bamford, D. H., and Chiu, W. (2015). Lemon-shaped halo archaeal virus His1 with uniform tail but variable capsid structure. Proc Natl Acad Sci U S A 112, 2449.

Huet, A., Conway, J. F., Letellier, L., and Boulanger, P. (2010). In vitro assembly of the $T=13$ procapsid of bacteriophage T5 with its scaffolding domain. J Virol 84, 9350.

Huet, A., Duda, R. L., Boulanger, P., and Conway, J. F. (2019). Capsid expansion of bacteriophage T5 revealed by high resolution cryoelectron microscopy. Proc Natl Acad Sci U S A 116, 21037.

Iranzo, J., Koonin, E. V., Prangishvili, D., and Krupovic, M. (2016a). Bipartite Network Analysis of the Archaeal Virosphere: Evolutionary Connections between Viruses and Capsidless Mobile Elements. J Virol 90, 11043. 
Iranzo, J., Krupovic, M., and Koonin, E. V. (2016b). The Double-Stranded DNA Virosphere as a Modular Hierarchical Network of Gene Sharing. mBio 7, e00978.

Iverson, E., and Stedman, K. (2012). A genetic study of SSV1, the prototypical fusellovirus. Front Microbiol $3,200$.

Iverson, E. A., Goodman, D. A., Gorchels, M. E., and Stedman, K. M. (2017a). Extreme Mutation Tolerance: Nearly Half of the Archaeal Fusellovirus Sulfolobus Spindle-Shaped Virus 1 Genes Are Not Required for Virus Function, Including the Minor Capsid Protein Gene vp3. J Virol 91, e02406.

Iverson, E. A., Goodman, D. A., Gorchels, M. E., and Stedman, K. M. (2017b). Genetic Analysis of the Major Capsid Protein of the Archaeal Fusellovirus SSV1: Mutational Flexibility and Conformational Change. Genes (Basel) 8, 373.

Jaatinen, S. T., Happonen, L. J., Laurinmaki, P., Butcher, S. J., and Bamford, D. H. (2008). Biochemical and structural characterisation of membrane-containing icosahedral dsDNA bacteriophages infecting thermophilic Thermus thermophilus. Virology 379, 10.

Kasson, P., DiMaio, F., Yu, X., Lucas-Staat, S., Krupovic, M., Schouten, S., Prangishvili, D., and Egelman, E. H. (2017). Model for a novel membrane envelope in a filamentous hyperthermophilic virus. Elife 6 , e26268.

Khayat, R., Fu, C. Y., Ortmann, A. C., Young, M. J., and Johnson, J. E. (2010). The architecture and chemical stability of the archaeal Sulfolobus turreted icosahedral virus. J Virol 84, 9575.

Khayat, R., Tang, L., Larson, E. T., Lawrence, C. M., Young, M., and Johnson, J. E. (2005). Structure of an archaeal virus capsid protein reveals a common ancestry to eukaryotic and bacterial viruses. Proc Natl Acad Sci U S A 102, 18944.

Kim, J. G., Kim, S. J., Cvirkaite-Krupovic, V., Yu, W. J., Gwak, J. H., López-Pérez, M., Rodriguez-Valera, F., Krupovic, M., Cho, J. C., and Rhee, S. K. (2019). Spindle-shaped viruses infect marine ammoniaoxidizing thaumarchaea. Proc Natl Acad Sci U S A 116, 15645.

Kohler, K., Meister, A., Dobner, B., Drescher, S., Ziethe, F., and Blume, A. (2006). Temperature-dependent aggregation behavior of symmetric long-chain bolaamphiphiles at the air-water interface. Langmuir 22, 2668.

Koonin, E. V., Dolja, V. V., Krupovic, M., Varsani, A., Wolf, Y. I., Yutin, N., Zerbini, F. M., and Kuhn, J. H. (2020). Global Organization and Proposed Megataxonomy of the Virus World. Microbiol Mol Biol Rev 84, e00061.

Krupovic, M., and Bamford, D. H. (2008a). Archaeal proviruses TKV4 and MVV extend the PRD1-adenovirus lineage to the phylum Euryarchaeota. Virology 375, 292.

Krupovic, M., and Bamford, D. H. (2008b). Virus evolution: how far does the double beta-barrel viral lineage extend? Nat Rev Microbiol 6, 941.

Krupovic, M., Cvirkaite-Krupovic, V., Iranzo, J., Prangishvili, D., and Koonin, E. V. (2018). Viruses of archaea: Structural, functional, environmental and evolutionary genomics. Virus Res 244, 181.

Krupovic, M., Dolja, V. V., and Koonin, E. V. (2020). The LUCA and its complex virome. Nat Rev Microbiol doi: 10.1038/s41579-020-0408-x.

Krupovic, M., Forterre, P., and Bamford, D. H. (2010). Comparative analysis of the mosaic genomes of tailed archaeal viruses and proviruses suggests common themes for virion architecture and assembly with tailed viruses of bacteria. J Mol Biol 397, 144.

Krupovic, M., and Koonin, E. V. (2017). Multiple origins of viral capsid proteins from cellular ancestors. Proc Natl Acad Sci U S A 114, E2401.

Krupovic, M., Makarova, K. S., Wolf, Y. I., Medvedeva, S., Prangishvili, D., Forterre, P., and Koonin, E. V. (2019). Integrated mobile genetic elements in Thaumarchaeota. Environ Microbiol 21, 2056.

Krupovic, M., Quemin, E. R., Bamford, D. H., Forterre, P., and Prangishvili, D. (2014). Unification of the globally distributed spindle-shaped viruses of the Archaea. J Virol 88, 2354.

Krupovic, M., Spang, A., Gribaldo, S., Forterre, P., and Schleper, C. (2011). A thaumarchaeal provirus testifies for an ancient association of tailed viruses with archaea. Biochem Soc Trans 39, 82.

Lander, G. C., Evilevitch, A., Jeembaeva, M., Potter, C. S., Carragher, B., and Johnson, J. E. (2008). Bacteriophage lambda stabilization by auxiliary protein gpD: timing, location, and mechanism of attachment determined by cryo-EM. Structure 16, 1399.

Laurinmäki, P. A., Huiskonen, J. T., Bamford, D. H., and Butcher, S. J. (2005). Membrane proteins modulate the bilayer curvature in the bacterial virus Bam35. Structure 13, 1819. 
Liu, J., Gao, R., Li, C., Ni, J., Yang, Z., Zhang, Q., Chen, H., and Shen, Y. (2017a). Functional assignment of multiple ESCRT-III homologs in cell division and budding in Sulfolobus islandicus. Mol Microbiol $105,540$.

Liu, Y., Brandt, D., Ishino, S., Ishino, Y., Koonin, E. V., Kalinowski, J., Krupovic, M., and Prangishvili, D. (2019). New archaeal viruses discovered by metagenomic analysis of viral communities in enrichment cultures. Environ Microbiol 21, 2002.

Liu, Y., Ishino, S., Ishino, Y., Pehau-Arnaudet, G., Krupovic, M., and Prangishvili, D. (2017b). A Novel Type of Polyhedral Viruses Infecting Hyperthermophilic Archaea. J Virol 91, e00589.

Liu, Y., Osinski, T., Wang, F., Krupovic, M., Schouten, S., Kasson, P., Prangishvili, D., and Egelman, E. H. (2018). Structural conservation in a membrane-enveloped filamentous virus infecting a hyperthermophilic acidophile. Nat Commun 9, 3360.

López-García, P., Knapp, S., Ladenstein, R., and Forterre, P. (1998). In vitro DNA binding of the archaeal protein Sso7d induces negative supercoiling at temperatures typical for thermophilic growth. Nucleic Acids Res 26, 2322.

Luk, A. W., Williams, T. J., Erdmann, S., Papke, R. T., and Cavicchioli, R. (2014). Viruses of haloarchaea. Life (Basel) 4, 681.

Maaty, W. S., Ortmann, A. C., Dlakic, M., Schulstad, K., Hilmer, J. K., Liepold, L., Weidenheft, B., Khayat, R., Douglas, T., Young, M. J., and Bothner, B. (2006). Characterization of the archaeal thermophile Sulfolobus turreted icosahedral virus validates an evolutionary link among double-stranded DNA viruses from all domains of life. J Virol 80, 7625.

Mizuno, C. M., Prajapati, B., Lucas-Staat, S., Sime-Ngando, T., Forterre, P., Bamford, D. H., Prangishvili, D., Krupovic, M., and Oksanen, H. M. (2019). Novel haloarchaeal viruses from Lake Retba infecting Haloferax and Halorubrum species. Environ Microbiol 21, 2129.

Mochizuki, T., Krupovic, M., Pehau-Arnaudet, G., Sako, Y., Forterre, P., and Prangishvili, D. (2012). Archaeal virus with exceptional virion architecture and the largest single-stranded DNA genome. Proc Natl Acad Sci U S A 109, 13386.

Mochizuki, T., Sako, Y., and Prangishvili, D. (2011). Provirus induction in hyperthermophilic archaea: characterization of Aeropyrum pernix spindle-shaped virus 1 and Aeropyrum pernix ovoid virus 1. J Bacteriol 193, 5412.

Mochizuki, T., Yoshida, T., Tanaka, R., Forterre, P., Sako, Y., and Prangishvili, D. (2010). Diversity of viruses of the hyperthermophilic archaeal genus Aeropyrum, and isolation of the Aeropyrum pernix bacilliform virus 1, APBV1, the first representative of the family Clavaviridae. Virology 402, 347.

Munson-McGee, J. H., Rooney, C., and Young, M. J. (2020). An Uncultivated Virus Infecting a Nanoarchaeal Parasite in the Hot Springs of Yellowstone National Park. J Virol 94, e01213.

Munson-McGee, J. H., Snyder, J. C., and Young, M. J. (2018). Archaeal Viruses from High-Temperature Environments. Genes (Basel) 9, 128.

Nadal, M., Mirambeau, G., Forterre, P., Reiter, W. D., and Duguet, M. (1986). Positively supercoiled DNA in a virus-like particle of an archaebacterium. Nature 21, 256.

Newcomb, W. W., Homa, F. L., and Brown, J. C. (2005). Involvement of the portal at an early step in herpes simplex virus capsid assembly. J Virol 79, 10540.

Nishimura, Y., Watai, H., Honda, T., Mihara, T., Omae, K., Roux, S., Blanc-Mathieu, R., Yamamoto, K., Hingamp, P., Sako, Y., Sullivan, M. B., Goto, S., Ogata, H., and Yoshida, T. (2017). Environmental Viral Genomes Shed New Light on Virus-Host Interactions in the Ocean. mSphere 2, e00359.

Oliveira, L., Tavares, P., and Alonso, J. C. (2013). Headful DNA packaging: bacteriophage SPP1 as a model system. Virus Res 173, 247.

Orlova, E. V., Gowen, B., Droge, A., Stiege, A., Weise, F., Lurz, R., van Heel, M., and Tavares, P. (2003). Structure of a viral DNA gatekeeper at 10 A resolution by cryo-electron microscopy. EMBO J 22, 1255.

Ortmann, A. C., Brumfield, S. K., Walther, J., McInnerney, K., Brouns, S. J., van de Werken, H. J., Bothner, B., Douglas, T., van de Oost, J., and Young, M. J. (2008). Transcriptome analysis of infection of the archaeon Sulfolobus solfataricus with Sulfolobus turreted icosahedral virus. J Virol 82, 4874.

Pauly, M. D., Bautista, M. A., Black, J. A., and Whitaker, R. J. (2019). Diversified local CRISPR-Cas immunity to viruses of Sulfolobus islandicus. Philos Trans R Soc Lond B Biol Sci 374, 20180093. 
Pawlowski, A., Rissanen, I., Bamford, J. K., Krupovic, M., and Jalasvuori, M. (2014).

Gammasphaerolipovirus, a newly proposed bacteriophage genus, unifies viruses of halophilic archaea and thermophilic bacteria within the novel family Sphaerolipoviridae. Arch Virol 159, 1541.

Pettersen, E. F., Goddard, T. D., Huang, C. C., Couch, G. S., Greenblatt, D. M., Meng, E. C., and Ferrin, T. E. (2004). UCSF Chimera--a visualization system for exploratory research and analysis. J Comput Chem 25, 1605.

Pfister, P., Wasserfallen, A., Stettler, R., and Leisinger, T. (1998). Molecular analysis of Methanobacterium phage psiM2. Mol Microbiol 30, 233.

Philosof, A., Yutin, N., Flores-Uribe, J., Sharon, I., Koonin, E. V., and Beja, O. (2017). Novel Abundant Oceanic Viruses of Uncultured Marine Group II Euryarchaeota. Curr Biol 27, 1362.

Pietila, M. K., Demina, T. A., Atanasova, N. S., Oksanen, H. M., and Bamford, D. H. (2014). Archaeal viruses and bacteriophages: comparisons and contrasts. Trends Microbiol 22, 334.

Pietilä, M. K., Laurinmaki, P., Russell, D. A., Ko, C. C., Jacobs-Sera, D., Butcher, S. J., Bamford, D. H., and Hendrix, R. W. (2013a). Insights into head-tailed viruses infecting extremely halophilic archaea. J Virol 87, 3248.

Pietilä, M. K., Laurinmaki, P., Russell, D. A., Ko, C. C., Jacobs-Sera, D., Hendrix, R. W., Bamford, D. H., and Butcher, S. J. (2013b). Structure of the archaeal head-tailed virus HSTV-1 completes the HK97 fold story. Proc Natl Acad Sci U S A 110, 10604.

Porter, K., and Dyall-Smith, M. L. (2008). Transfection of haloarchaea by the DNAs of spindle and round haloviruses and the use of transposon mutagenesis to identify non-essential regions. Mol Microbiol 70, 1236.

Porter, K., Kukkaro, P., Bamford, J. K., Bath, C., Kivelä, H. M., Dyall-Smith, M. L., and Bamford, D. H. (2005). SH1: A novel, spherical halovirus isolated from an Australian hypersaline lake. Virology 335, 22.

Prangishvili, D., Arnold, H. P., Götz, D., Ziese, U., Holz, I., Kristjansson, J. K., and Zillig, W. (1999). A novel virus family, the Rudiviridae: Structure, virus-host interactions and genome variability of the sulfolobus viruses SIRV1 and SIRV2. Genetics 152, 1387.

Prangishvili, D., Bamford, D. H., Forterre, P., Iranzo, J., Koonin, E. V., and Krupovic, M. (2017). The enigmatic archaeal virosphere. Nat Rev Microbiol 15, 724.

Prangishvili, D., and Krupovic, M. (2012). A new proposed taxon for double-stranded DNA viruses, the order "Ligamenvirales". Arch Virol 157, 791.

Prangishvili, D., Krupovic, M., and ICTV Report Consortium. (2018a). ICTV Virus Taxonomy Profile: Ampullaviridae. J Gen Virol 99, 288.

Prangishvili, D., Krupovic, M., and ICTV Report Consortium. (2018b). ICTV Virus Taxonomy Profile: Bicaudaviridae. J Gen Virol 99, 864.

Prangishvili, D., Krupovic, M., and ICTV Report Consortium. (2018c). ICTV Virus Taxonomy Profile: Globuloviridae. J Gen Virol 99, 1357.

Prangishvili, D., Mochizuki, T., Krupovic, M., and ICTV Report Consortium. (2018d). ICTV Virus Taxonomy Profile: Guttaviridae. J Gen Virol 99, 290.

Prangishvili, D., Mochizuki, T., Liu, Y., Krupovic, M., and ICTV Report Consortium. (2019a). ICTV Virus Taxonomy Profile: Clavaviridae. J Gen Virol 100, 1267.

Prangishvili, D., Rensen, E., Mochizuki, T., Krupovic, M., and ICTV Report Consortium. (2019b). ICTV Virus Taxonomy Profile: Tristromaviridae. J Gen Virol 100, 135.

Prangishvili, D., Vestergaard, G., Häring, M., Aramayo, R., Basta, T., Rachel, R., and Garrett, R. A. (2006). Structural and genomic properties of the hyperthermophilic archaeal virus ATV with an extracellular stage of the reproductive cycle. J Mol Biol 359, 1203.

Ptchelkine, D., Gillum, A., Mochizuki, T., Lucas-Staat, S., Liu, Y., Krupovic, M., Phillips, S. E. V., Prangishvili, D., and Huiskonen, J. T. (2017). Unique architecture of thermophilic archaeal virus APBV1 and its genome packaging. Nat Commun 8, 1436.

Quemin, E. R., Chlanda, P., Sachse, M., Forterre, P., Prangishvili, D., and Krupovic, M. (2016). EukaryoticLike Virus Budding in Archaea. mBio 7, e01439.

Quemin, E. R., Lucas, S., Daum, B., Quax, T. E., Kuhlbrandt, W., Forterre, P., Albers, S. V., Prangishvili, D., and Krupovic, M. (2013). First insights into the entry process of hyperthermophilic archaeal viruses. J Virol 87, 13379. 
Quemin, E. R., Pietilä, M. K., Oksanen, H. M., Forterre, P., Rijpstra, W. I., Schouten, S., Bamford, D. H., Prangishvili, D., and Krupovic, M. (2015). Sulfolobus Spindle-Shaped Virus 1 Contains Glycosylated Capsid Proteins, a Cellular Chromatin Protein, and Host-Derived Lipids. J Virol 89, 11681.

Rao, V. B., and Feiss, M. (2015). Mechanisms of DNA Packaging by Large Double-Stranded DNA Viruses. Annu Rev Virol 2, 351.

Redder, P., Peng, X., Brugger, K., Shah, S. A., Roesch, F., Greve, B., She, Q., Schleper, C., Forterre, P., Garrett, R. A., and Prangishvili, D. (2009). Four newly isolated fuselloviruses from extreme geothermal environments reveal unusual morphologies and a possible interviral recombination mechanism. Environ Microbiol 11, 2849.

Reiter, W. D., Palm, P., Henschen, A., Lottspeich, F., Zillig, W., and Grampp, B. (1987). Identification and characterization of the genes encoding three structural proteins of the Sulfolobus virus-like particle SSV1. Mol Gen Genet 206, 144.

Rensen, E., Krupovic, M., and Prangishvili, D. (2015). Mysterious hexagonal pyramids on the surface of Pyrobaculum cells. Biochimie 118, 365.

Rensen, E. I., Mochizuki, T., Quemin, E., Schouten, S., Krupovic, M., and Prangishvili, D. (2016). A virus of hyperthermophilic archaea with a unique architecture among DNA viruses. Proc Natl Acad Sci U S A 113, 2478.

Rice, G., Tang, L., Stedman, K., Roberto, F., Spuhler, J., Gillitzer, E., Johnson, J. E., Douglas, T., and Young, M. (2004). The structure of a thermophilic archaeal virus shows a double-stranded DNA viral capsid type that spans all domains of life. Proc Natl Acad Sci U S A 101, 7716.

Rissanen, I., Grimes, J. M., Pawlowski, A., Mäntynen, S., Harlos, K., Bamford, J. K., and Stuart, D. I. (2013). Bacteriophage P23-77 capsid protein structures reveal the archetype of an ancient branch from a major virus lineage. Structure 21, 718.

Rowland, E. F., Bautista, M. A., Zhang, C., and Whitaker, R. J. (2020). Surface resistance to SSVs and SIRVs in pilin deletions of Sulfolobus islandicus. Mol Microbiol 113, 718.

San Martín, C., Huiskonen, J. T., Bamford, J. K., Butcher, S. J., Fuller, S. D., Bamford, D. H., and Burnett, R. M. (2002). Minor proteins, mobile arms and membrane-capsid interactions in the bacteriophage PRD1 capsid. Nat Struct Biol 9, 756.

Santos-Pérez, I., Charro, D., Gil-Carton, D., Azkargorta, M., Elortza, F., Bamford, D. H., Oksanen, H. M., and Abrescia, N. G. A. (2019). Structural basis for assembly of vertical single $\beta$-barrel viruses. Nat Commun 10, 1184.

Schleper, C., Kubo, K., and Zillig, W. (1992). The particle SSV1 from the extremely thermophilic archaeon Sulfolobus is a virus: demonstration of infectivity and of transfection with viral DNA. Proc Natl Acad Sci U S A 89, 7645.

Senčilo, A., Jacobs-Sera, D., Russell, D. A., Ko, C. C., Bowman, C. A., Atanasova, N. S., Osterlund, E., Oksanen, H. M., Bamford, D. H., Hatfull, G. F., Roine, E., and Hendrix, R. W. (2013). Snapshot of haloarchaeal tailed virus genomes. RNA Biol 10, 803.

Senčilo, A., and Roine, E. (2014). A glimpse of the genomic diversity of haloarchaeal tailed viruses. Front Microbiol 5, 84.

Snyder, J. C., Samson, R. Y., Brumfield, S. K., Bell, S. D., and Young, M. J. (2013). Functional interplay between a virus and the ESCRT machinery in archaea. Proc Natl Acad Sci U S A 110, 10783.

Stedman, K. M. (2011). Fusellovirus. In The Springer Index of Viruses (C. Tidona, and G. Darai, eds.), pp. https://doi.org/10.1007/978. Springer, New York, NY.

Stedman, K. M., DeYoung, M., Saha, M., Sherman, M. B., and Morais, M. C. (2015). Structural insights into the architecture of the hyperthermophilic Fusellovirus SSV1. Virology 474, 105.

Steven, A. C., Heymann, J. B., Cheng, N., Trus, B. L., and Conway, J. F. (2005). Virus maturation: dynamics and mechanism of a stabilizing structural transition that leads to infectivity. Curr Opin Struct Biol 15, 227.

Stromsten, N. J., Bamford, D. H., and Bamford, J. K. (2003). The unique vertex of bacterial virus PRD1 is connected to the viral internal membrane. J Virol 77, 6314.

Strömsten, N. J., Bamford, D. H., and Bamford, J. K. (2005). In vitro DNA packaging of PRD1: a common mechanism for internal-membrane viruses. J Mol Biol 348, 617.

Szymczyna, B. R., Taurog, R. E., Young, M. J., Snyder, J. C., Johnson, J. E., and Williamson, J. R. (2009). Synergy of NMR, computation, and X-ray crystallography for structural biology. Structure 17, 499. 
Tang, S. L., Nuttall, S., and Dyall-Smith, M. (2004). Haloviruses HF1 and HF2: evidence for a recent and large recombination event. J Bacteriol 186, 2810.

Tavares, P. (2018). The Bacteriophage Head-to-Tail Interface. Subcell Biochem 88, 305.

Thiroux, S., Dupont, S., Nesb $\varnothing$, C. L., Bienvenu, N., Krupovic, M., L'Haridon, S., Marie, D., Forterre, P., Godfroy, A., and Geslin, C. (2020). The first head-tailed virus, MFTV1, produced by a hyperthermophilic methanogenic deep-sea archaea. In revission.

Uldahl, K. B., Jensen, S. B., Bhoobalan-Chitty, Y., Martínez-Álvarez, L., Papathanasiou, P., and Peng, X. (2016). Life Cycle Characterization of Sulfolobus Monocaudavirus 1, an Extremophilic SpindleShaped Virus with Extracellular Tail Development. J Virol 90, 5693.

Veesler, D., Ng, T.-S., Sendamarai, A. K., Eilers, B. J., Lawrence, C. M., Lok, S.-M., Young, M. J., Johnson, J. E., and Fu, C. (2013). Atomic structure of the 75 MDa extremophile Sulfolobus turreted icosahedral virus determined by CryoEM and X-ray crystallography. Proc Natl Acad Sci U S A 110, 5504.

Vik, D. R., Roux, S., Brum, J. R., Bolduc, B., Emerson, J. B., Padilla, C. C., Stewart, F. J., and Sullivan, M. B. (2017). Putative archaeal viruses from the mesopelagic ocean. PeerJ 5, e3428.

Wagner, C., Reddy, V., Asturias, F., Khoshouei, M., Johnson, J. E., Manrique, P., Munson-McGee, J., Baumeister, W., Lawrence, C. M., and Young, M. J. (2017). Isolation and characterization of Metallosphaera turreted icosahedral virus, a founding member of a new family of archaeal viruses. J Virol 91, e00925.

Wang, F., Baquero, D. P., Beltran, L. C., Su, Z., Osinski, T., Zheng, W., Prangishvili, D., Krupovic, M., and Egelman, E. H. (2020a). Structures of filamentous viruses infecting hyperthermophilic archaea explain DNA stabilization in extreme environments. Proc Natl Acad Sci U S A 117, 19643.

Wang, F., Baquero, D. P., Su, Z., Beltran, L. C., Prangishvili, D., Krupovic, M., and Egelman, E. H. (2020b). The structures of two archaeal type IV pili illuminate evolutionary relationships. Nat Commun 11, 3424.

Wang, F., Baquero, D. P., Su, Z., Osinski, T., Prangishvili, D., Egelman, E. H., and Krupovic, M. (2020c). Structure of a filamentous virus uncovers familial ties within the archaeal virosphere. Virus Evol 6, veaa023.

Wang, F., Cvirkaite-Krupovic, V., Kreutzberger, M. A. B., Su, Z., de Oliveira, G. A. P., Osinski, T., Sherman, N., DiMaio, F., Wall, J. S., Prangishvili, D., Krupovic, M., and Egelman, E. H. (2019a). An extensively glycosylated archaeal pilus survives extreme conditions. Nat Microbiol 4, 1401.

Wang, F., Liu, Y., Su, Z., Osinski, T., de Oliveira, G. A. P., Conway, J. F., Schouten, S., Krupovic, M., Prangishvili, D., and Egelman, E. H. (2019b). A packing for A-form DNA in an icosahedral virus. Proc Natl Acad Sci U S A 116, 22591.

Wang, H., Guo, Z., Feng, H., Chen, Y., Chen, X., Li, Z., Hernández-Ascencio, W., Dai, X., Zhang, Z., Zheng, X., Mora-López, M., Fu, Y., Zhang, C., Zhu, P., and Huang, L. (2018). Novel Sulfolobus virus with an exceptional capsid architecture. J Virol 92, e01727.

Wang, H., Peng, N., Shah, S. A., Huang, L., and She, Q. (2015). Archaeal extrachromosomal genetic elements. Microbiol Mol Biol Rev 79, 117.

Weidenbach, K., Nickel, L., Neve, H., Alkhnbashi, O. S., Kunzel, S., Kupczok, A., Bauersachs, T., Cassidy, L., Tholey, A., Backofen, R., and Schmitz, R. A. (2017). Methanosarcina Spherical Virus, a Novel Archaeal Lytic Virus Targeting Methanosarcina Strains. J Virol 91.

White, H. E., Sherman, M. B., Brasiles, S., Jacquet, E., Seavers, P., Tavares, P., and Orlova, E. V. (2012). Capsid structure and its stability at the late stages of bacteriophage SPP1 assembly. J Virol 86, 6768.

Wiedenheft, B., Stedman, K., Roberto, F., Willits, D., Gleske, A. K., Zoeller, L., Snyder, J., Douglas, T., and Young, M. (2004). Comparative genomic analysis of hyperthermophilic archaeal Fuselloviridae viruses. J Virol 78, 1954.

Wikoff, W. R., Liljas, L., Duda, R. L., Tsuruta, H., Hendrix, R. W., and Johnson, J. E. (2000). Topologically linked protein rings in the bacteriophage HK97 capsid. Science 289, 2129.

Wolf, S., Fischer, M. A., Kupczok, A., Reetz, J., Kern, T., Schmitz, R. A., and Rother, M. (2019). Characterization of the lytic archaeal virus Drs3 infecting Methanobacterium formicicum. Arch Virol 164, 667. 
Xiang, X., Chen, L., Huang, X., Luo, Y., She, Q., and Huang, L. (2005). Sulfolobus tengchongensis spindleshaped virus STSV1: virus-host interactions and genomic features. J Virol 79, 8677.

$\mathrm{Xu}$, J., Hendrix, R. W., and Duda, R. L. (2004). Conserved translational frameshift in dsDNA bacteriophage tail assembly genes. Mol Cell 16, 11.

Xu, J., Hendrix, R. W., and Duda, R. L. (2013). A balanced ratio of proteins from gene G and frameshiftextended gene GT is required for phage lambda tail assembly. J Mol Biol 425, 3476.

Yutin, N., Backstrom, D., Ettema, T. J. G., Krupovic, M., and Koonin, E. V. (2018). Vast diversity of prokaryotic virus genomes encoding double jelly-roll major capsid proteins uncovered by genomic and metagenomic sequence analysis. Virol J 15, 67.

Zhang, J., Zheng, X., Wang, H., Jiang, H., Dong, H., and Huang, L. (2020a). Novel Sulfolobus Fuselloviruses with Extensive Genomic Variations. J Virol 94, e01624.

Zhang, Z., Liu, Y., Wang, S., Yang, D., Cheng, Y., Hu, J., Chen, J., Mei, Y., Shen, P., Bamford, D. H., and Chen, $X$. (2012). Temperate membrane-containing halophilic archaeal virus SNJ1 has a circular dsDNA genome identical to that of plasmid pHH205. Virology 434, 233.

Zhang, Z., Zhan, Z., Wang, B., Chen, Y., Chen, X., Wan, C., Fu, Y., and Huang, L. (2020b). Archaeal Chromatin Proteins Cren7 and Sul7d Compact DNA by Bending and Bridging. mBio 11, e00804. 


\section{Viruses of Euryarchaeota}

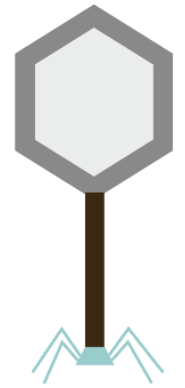

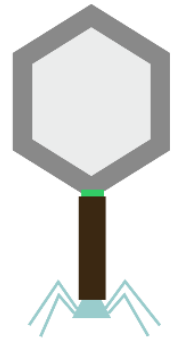

Myoviridae

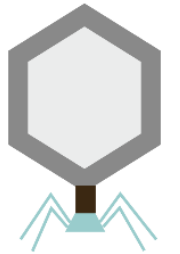

Podoviridae
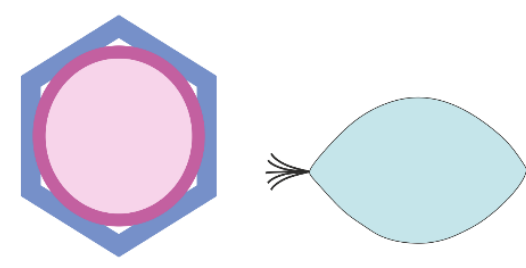

Halspiviridae

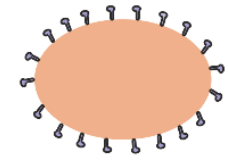

Pleolipoviridae

\section{Simuloviridae}

\section{Viruses of Crenarchaeota}

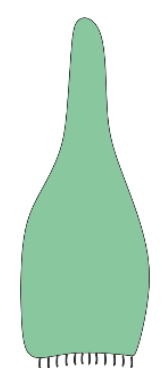

\section{Ampullaviridae}

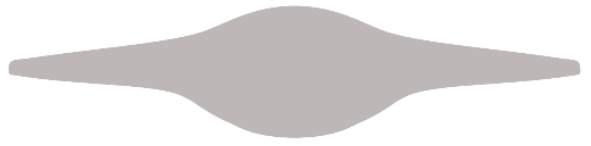

Bicaudaviridae

$\geqslant$

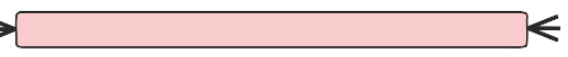

Rudiviridae

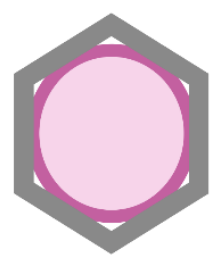

Turriviridae

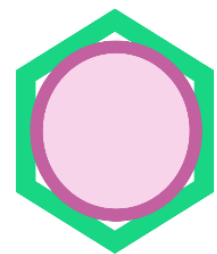

Portogloboviridae

Ovaliviridae

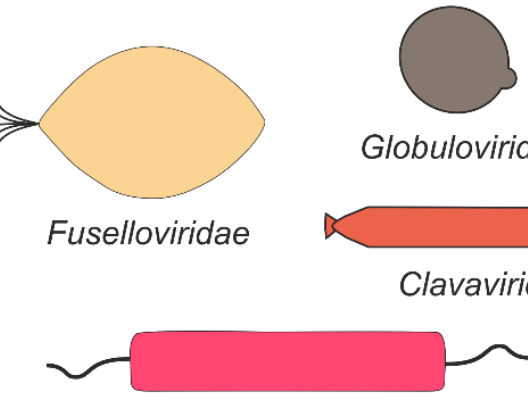

Globuloviridae

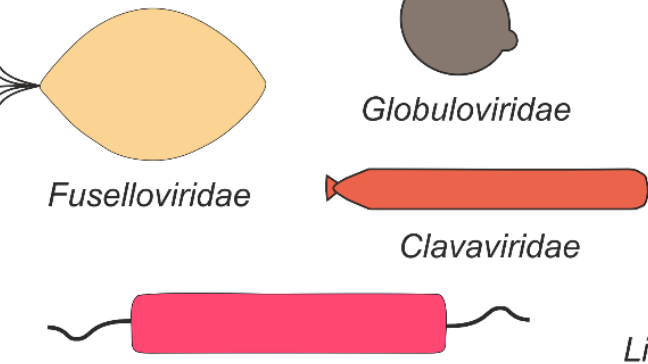

Clavaviridae

Tristromaviridae
Fuselloviridae

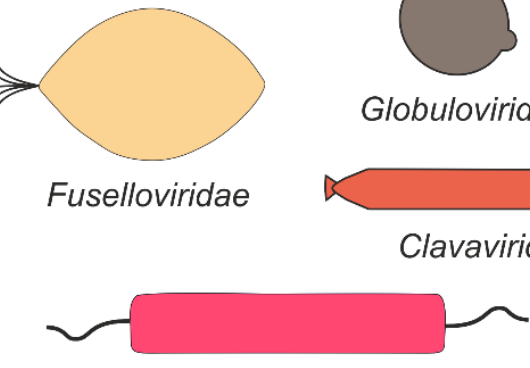

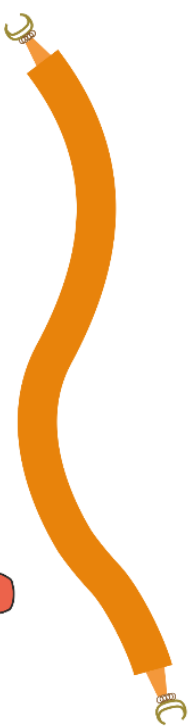

Lipothrixviridae

\section{Viruses of Thaumarchaeota}

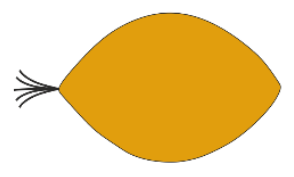

Thaspiviridae

Figure 1. Representation of virion morphotypes of archaeal viruses infecting members of the phyla Euryarchaeota, Crenarchaeota and Thaumarchaeota. Names of viral families are indicated below the schematic virus particles. 
A

HSTV-2

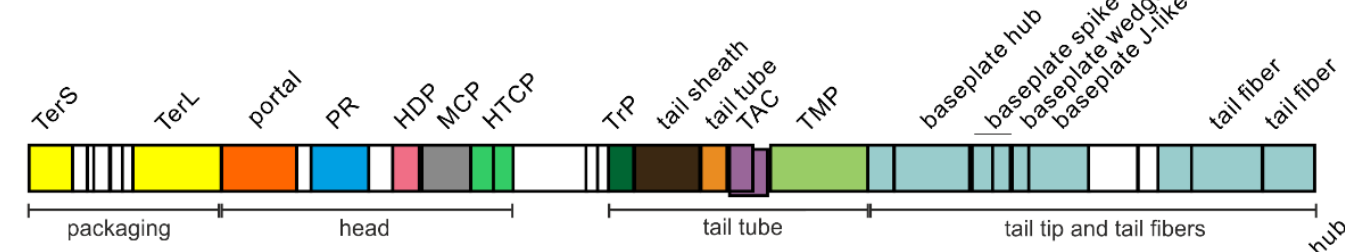

HFTV1

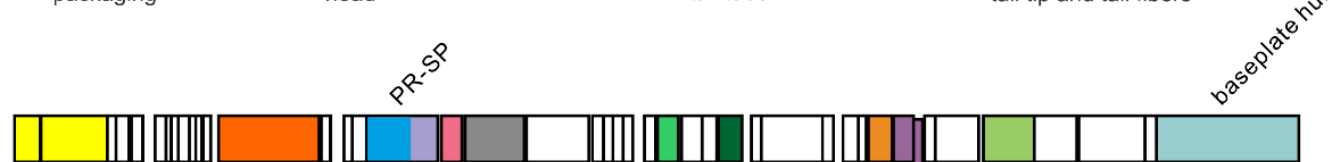

$\mathrm{Mu}$

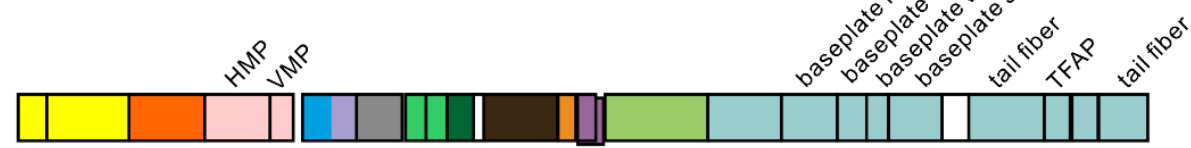

HK97

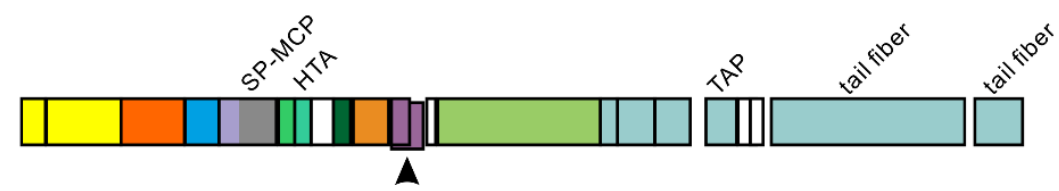

B

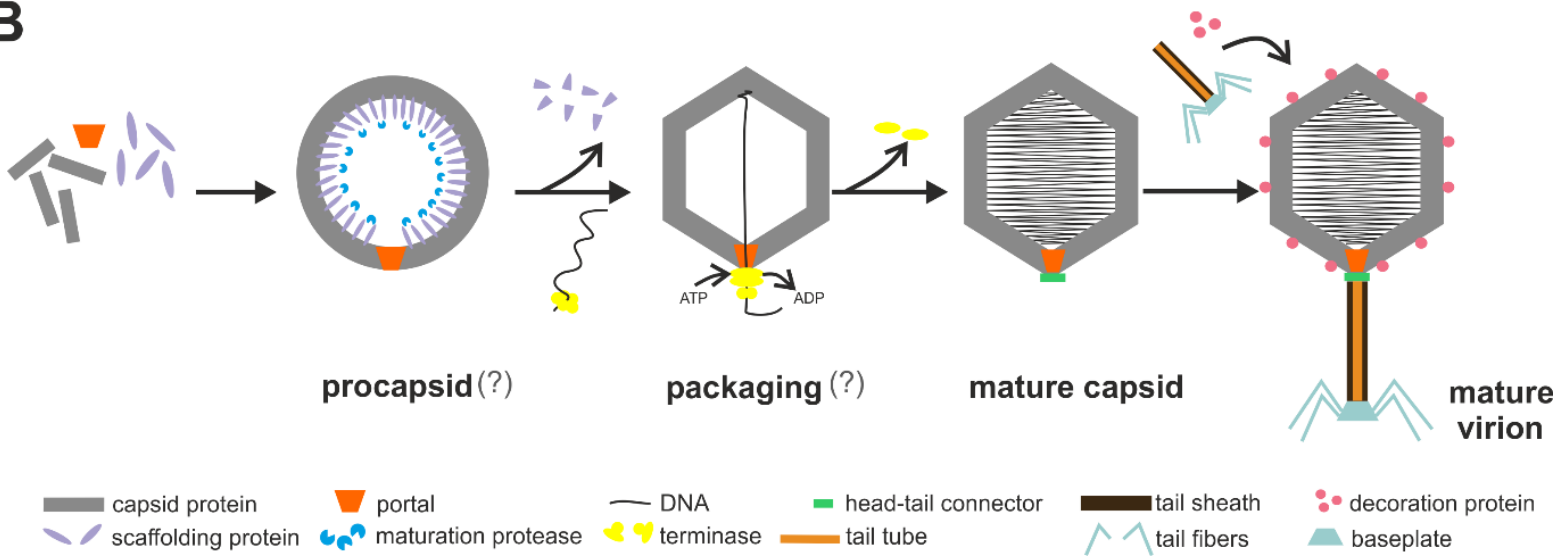

Figure 2. Assembly of head-tailed viruses. A. Comparison of the capsid and tail morphogenesis modules of headtailed viruses infecting archaea and bacteria. The morphogenesis modules of archaeal viruses Halorubrum sodomense tailed virus 2 (HSTV-2) and Haloferax tailed virus 1 (HFTV1) are presented at the top and compared to those of bacteriophages $\mathrm{Mu}$ and HK97. The open reading fragments (ORFs) are represented with rectangles. The functional annotations of the predicted ORFs are color-coded and depicted above the corresponding ORFs (TerS and TerL, small and large terminase subunits, respectively; PR, prohead protease; HDP, head decoration protein; MCP, major capsid protein; SP, scaffolding protein/domain; HTCP, head-tail connector protein; TrP, tail termination protein; TAC, tail assembly chaperone; TMP, tape measure protein; PR-SP, prohead protease-scaffolding protein fusion; HMP, head morphogenesis protein; VMP, virion morphogenesis protein; TFAP, tail fiber assembly protein; HTA, head-tail adaptor; TAP, tail assembly protein). Genes encoding tail tip and tail fiber proteins are shown in blue sapphire. Translational frameshifts are indicated with a black triangle under the corresponding ORFs. Each region is depicted proportional to the size of the gene. B. Schematic representation of head-tailed virus assembly. The process starts with the formation of an empty procapsid when multiple copies of the capsid/scaffold complex bind to the portal protein. During or before DNA packaging, the scaffolding protein is proteolytically cleaved by the viral maturation/prohead protease. Once the procapsid is assembled, the viral genome is translocated into the capsid by the action of the packaging complex, which uses ATP hydrolysis. After packaging, the decoration proteins bind to the capsid and the tail, which is assembled separately, is attached to the capsid to produce a mature infectious virus. 
A

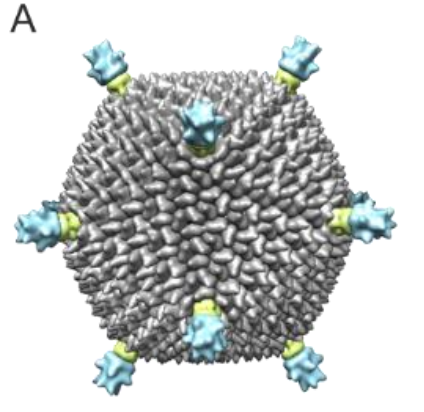

B

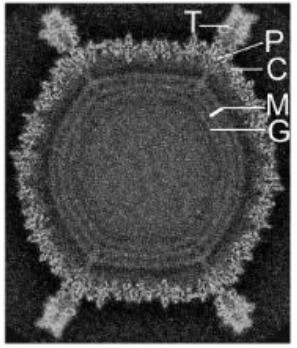

$E$

Erocapsid
C

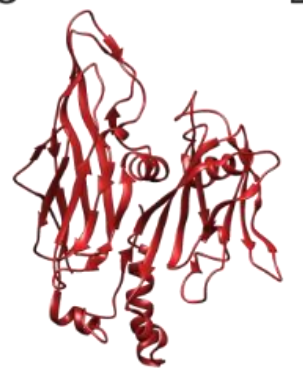

D

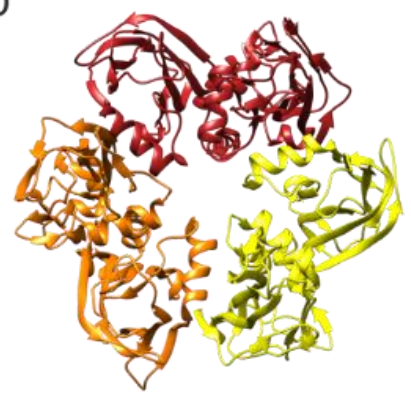

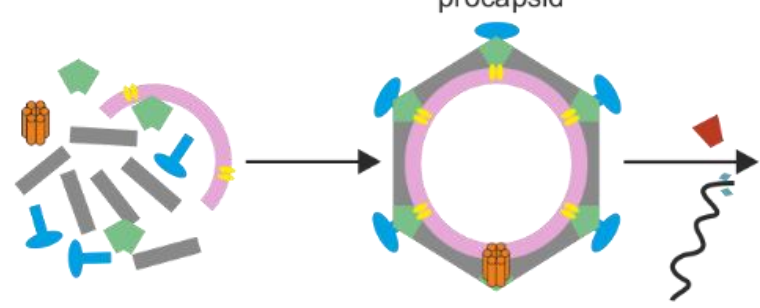

genome packaging

mature virion

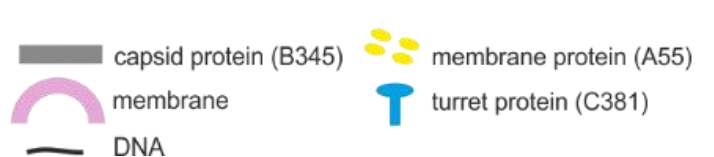

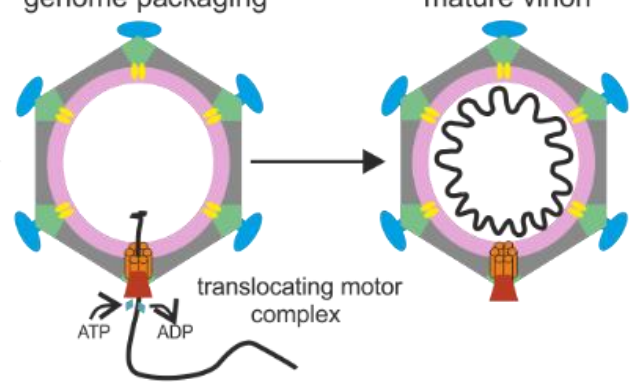

transmembrane pore $\because$ genome recognition protein (A78)

penton protein (A223) genome-packaging NTPase (B204)

Figure 3. Cryo-EM reconstruction of the icosahedral virion of Sulfolobus turreted icosahedral virus (STIV) and the mechanism of its assembly. A. Overall view of the cryo-EM density map of STIV rendered to show the capsid shell. MCP is depicted in grey, turrets are colored in light blue and pentons in lime green. B. Cross-section of the cryo-EM density map revealing the internal structure of the STIV virions. T, turrets; P, pentons; C, capsid; M, membrane and G, genome. EMDB accession number for the STIV cryo-EM reconstruction: EMD-5584. C. Ribbon representation of the STIV major capsid protein B345 (PDB entry: 3j31). D. Ribbon representation of the STIV MCP trimer. Each subunit is depicted with a different color. The images were generated using UCSF Chimera (Pettersen et al., 2004). E. Schematic model of STIV virion assembly and genome packaging. STIV assembly initiates with the formation of an empty procapsid composed of the major capsid protein (B345), turret protein (C381), penton base protein (A223) and an internal membrane with predicted proteins attached to it (A55). In addition, the presence of a transmembrane pore formed in the viral membrane has been suggested for the genome translocation at the packaging vertex. Simultaneously with the formation of the procapsid, the genome recognition protein A78 (B72 in STIV2) binds to the genome and recruits it to a unique motor complex formed by the DNA packaging ATPase B204. The STIV genome is translocated into the procapsid with the help of the ATP hydrolysis and mature virions are formed. The STIV genome is presumably circularized inside of the capsid by an unknown mechanism. 

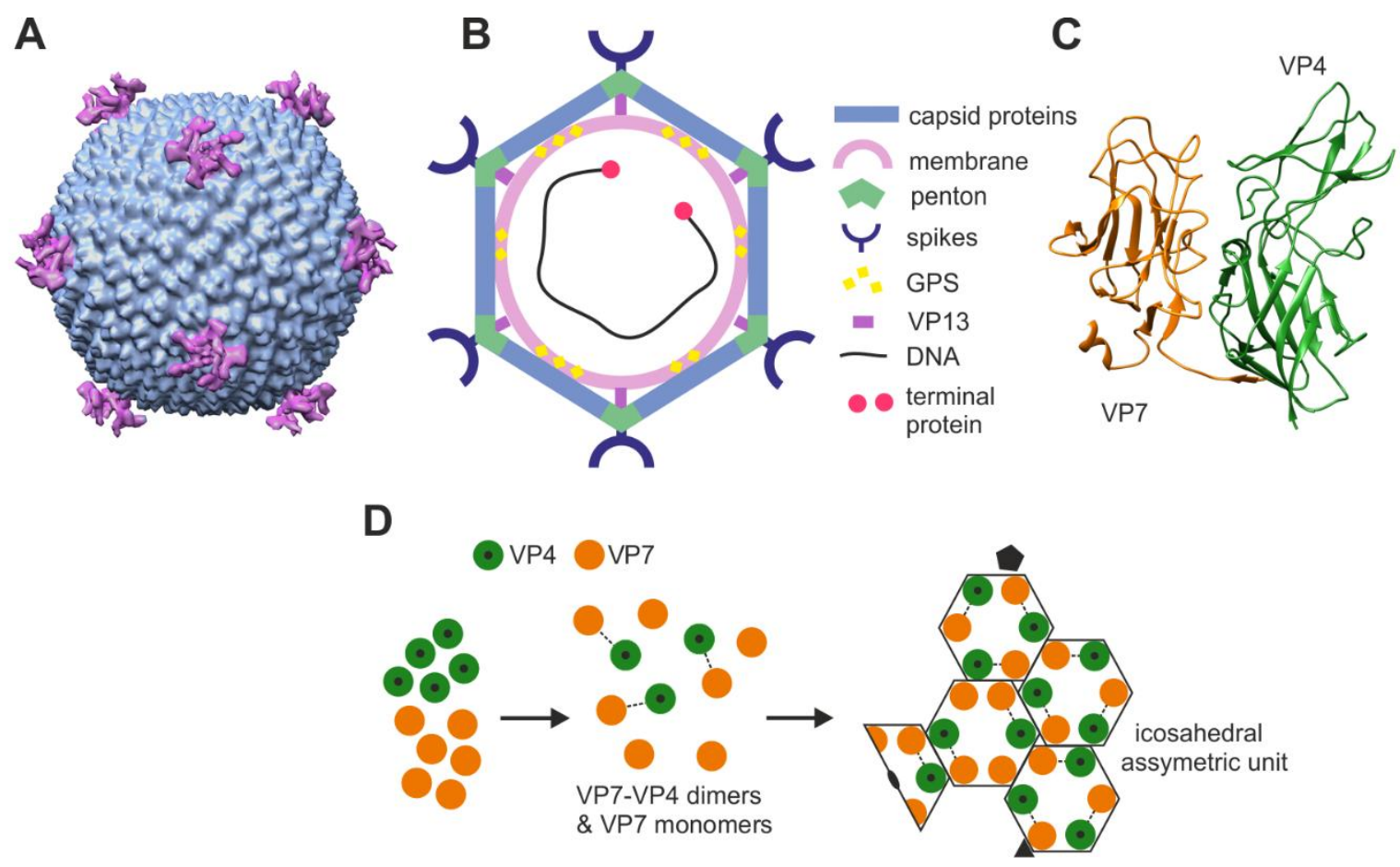

Figure 4. Cryo-EM reconstruction of the icosahedral virion of Haloarcula hispanica icosahedral virus 2 (HHIV-2). A. Overall view of the cryo-EM density map of HHIV-2 rendered to show the capsid shell. The capsid is depicted in blue whereas the spike complex is in purple. EMDB accession number for the HHIV-2 full map: EMD-0172 B. Schematic cross-section of the sphaerolipovirus particle, revealing its internal organization. C. Ribbon representation of the HHIV-2 major capsid proteins VP4 and VP7 (PDB entry: 6H82). The images were generated using Chimera (Pettersen et al., 2004). D. Schematic of the icosahedral asymmetric unit of HHIV-2. VP4 and VP7 MCPs are shown as green and orange circles, respectively, whereas additional $\beta$-barrel in VP4, which forms the tower, is represented by a black circle. The two MCPs form pseudo-hexagonal three-tower and two-tower capsomers. The three-tower capsomers are composed of three alternating VP7-VP4 heterodimers, whereas the two-tower capsomers consist of two VP7-VP4 heterodimers separated by two VP7 monomers. The icosahedral symmetry axes are depicted as follows: black triangle, three-fold; black pentagon, five-fold; ellipsoid, two-fold. 
A

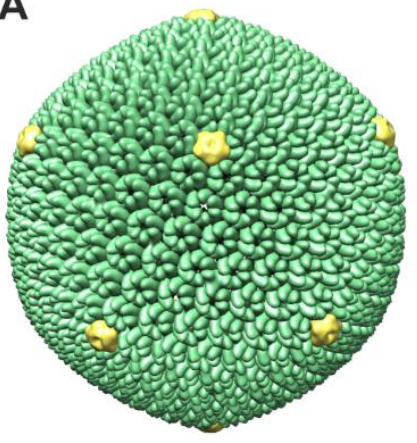

D

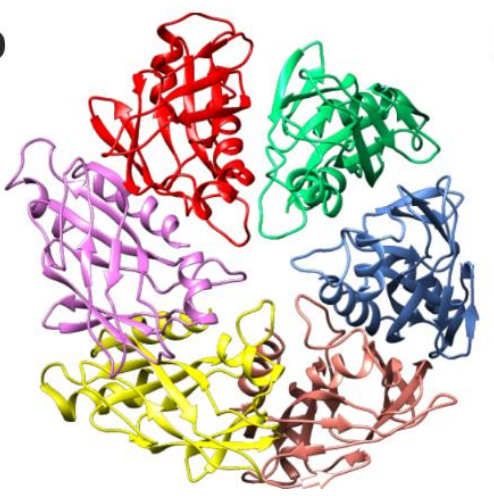

B

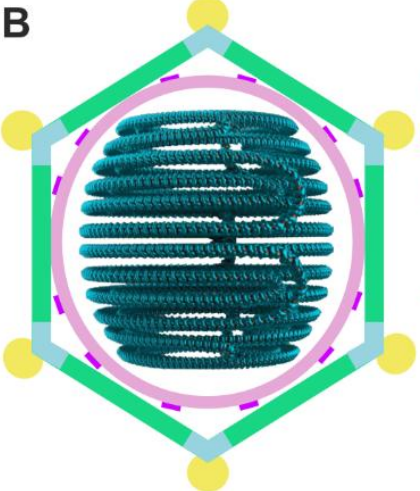

$\mathbf{E}$
C

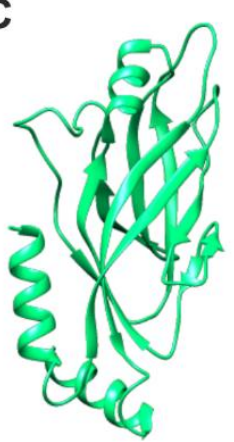

capsid protein (VP4)

- sub-capsomer protein

membrane

vertex complexes

dsDNA-VP1 complex

penton protein (VP10)

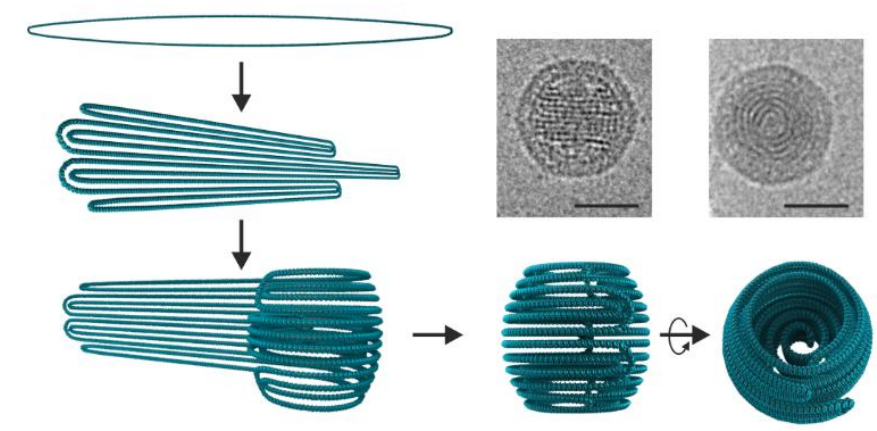

Figure 5. Cryo-EM reconstruction of the icosahedral virion of Sulfolobus polyhedral virus 1 (SPV1). A. Overall view of the cryo-EM density map of SPV1 rendered to show the capsid shell. The capsid is depicted in mint green whereas the vertex complex is in light yellow. EMDB accession number for the SPV1 full map: EMD-20083. B. Schematic cross-section of a SPV1 particle, revealing its internal organization. C. Ribbon representation of the SPV1 MCP VP4 (PDB entry: 6Oj0). D. Ribbon representation of the SPV1 MCP homohexamer. Each subunit is depicted with a different color. E. Schematic model for the STIV DNA packing. Bars, $50 \mathrm{~nm}$. 
A

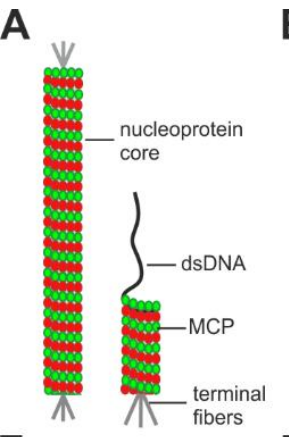

E

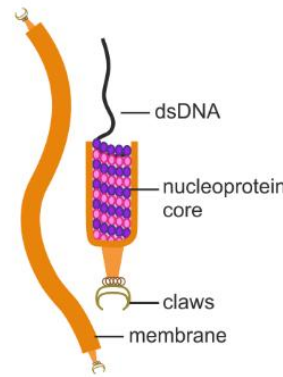

B

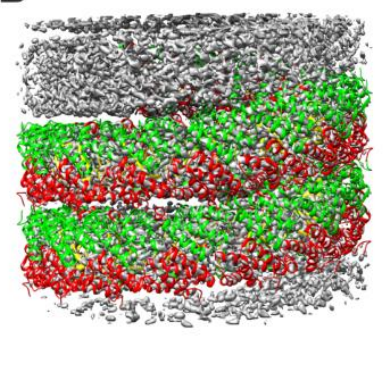

F

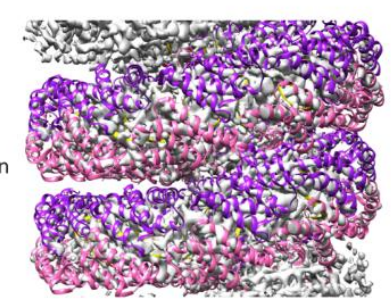

C

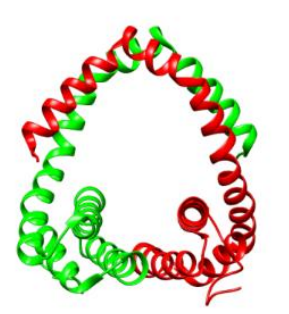

G

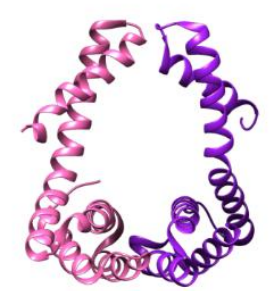

D

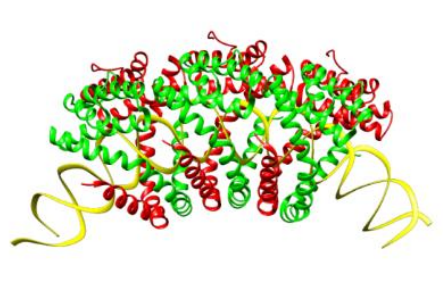

H
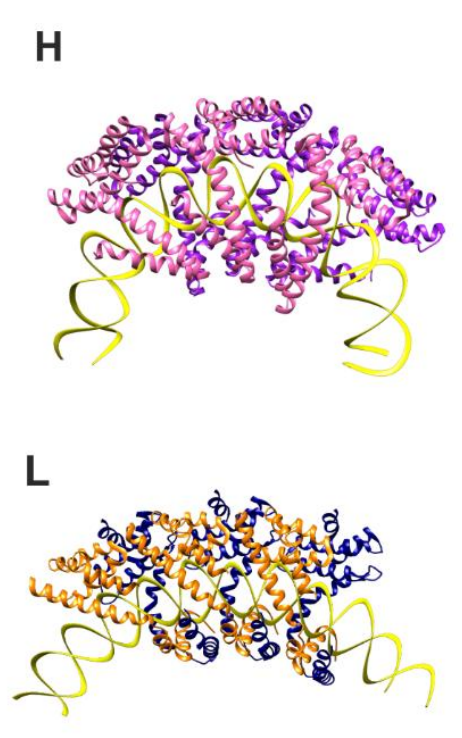

\section{L}

M
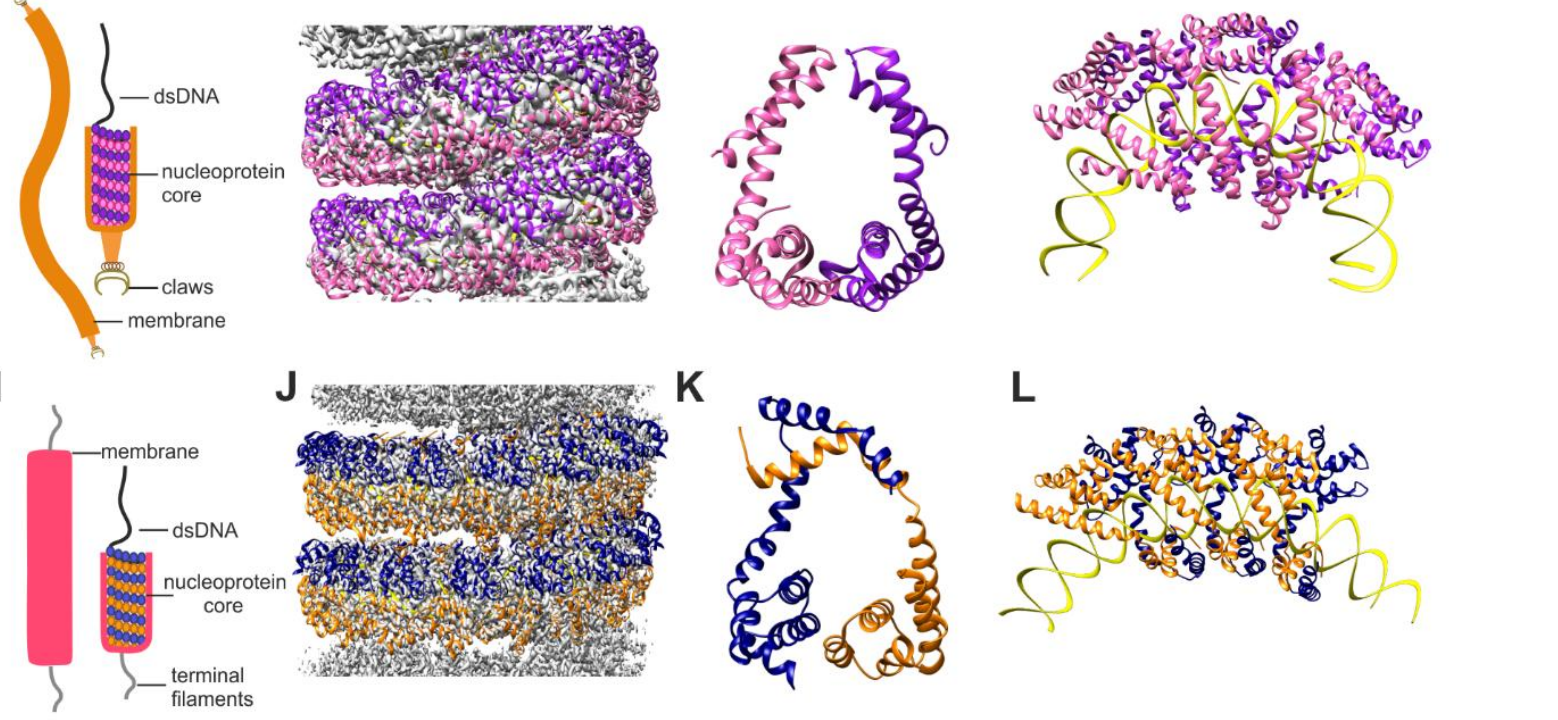

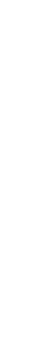

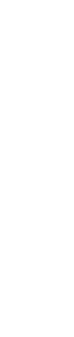

. 
A
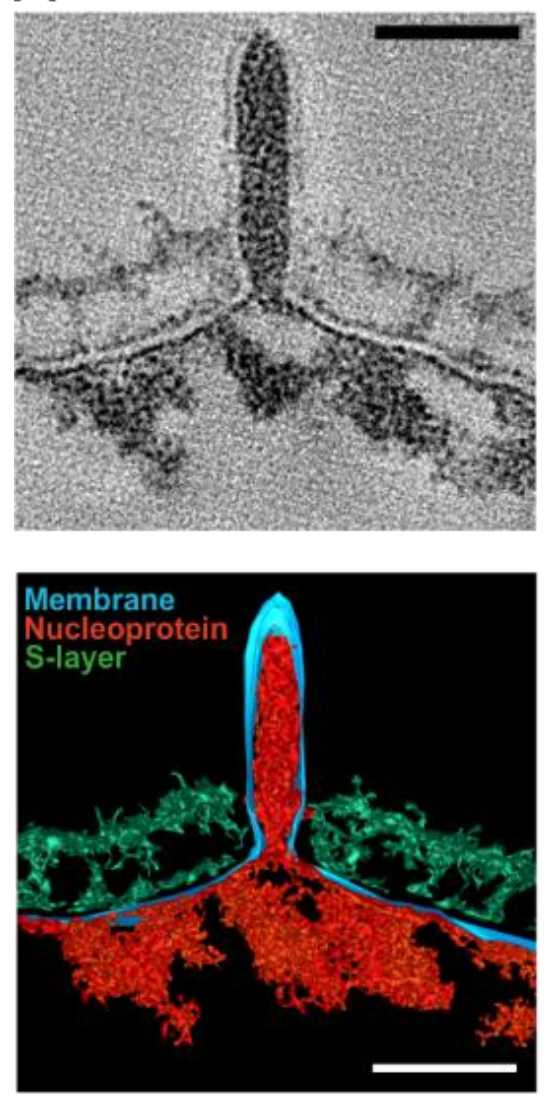

B
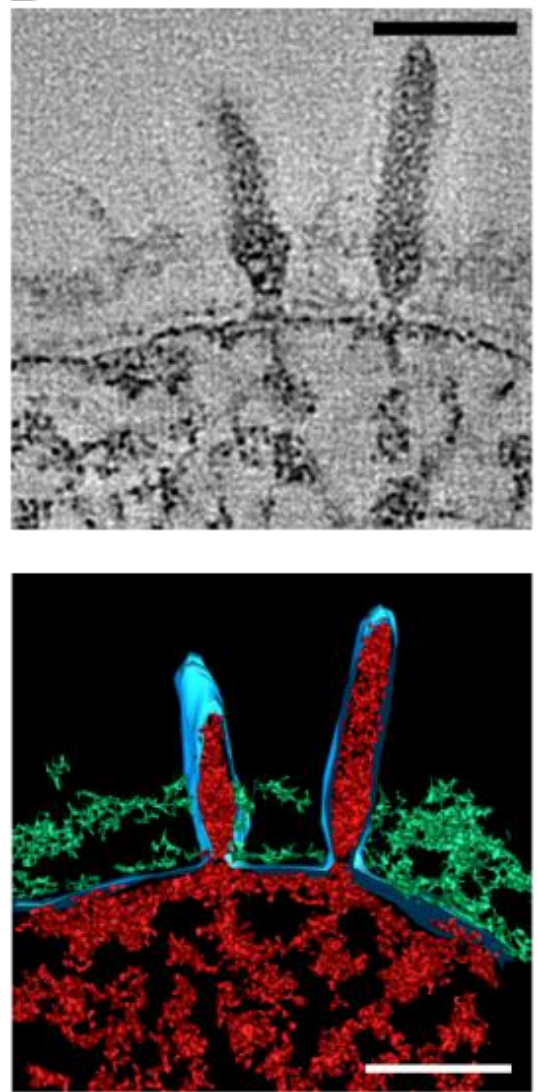

C
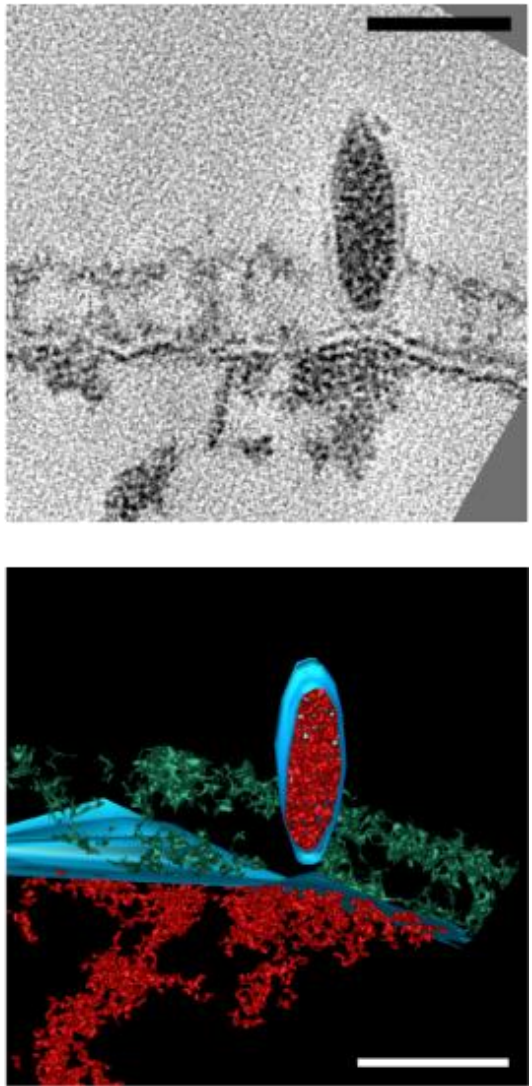

Figure 7. Budding of the Sulfolobus spindle-shaped virus 1 (SSV1). Slices through tomograms (top) and volume segmentations (bottom) show concomitant assembly and release of SSV1 virions. A. SSV1 virions are attached to the host cell surface, with the viral membrane being continuous with the cell membrane. B. Constricted budding neck at the trailing end of the SSV1 virion bud. C. SSV1 virion separated from the cell membrane. Scale bars, $50 \mathrm{~nm}$. Image modified from (Quemin et al., 2016) [Quemin, E.R., Chlanda, P., Sachse, M., Forterre, P., Prangishvili, D., and Krupovic, M. (2016). Eukaryotic-Like Virus Budding in Archaea. mBio 7, e01439-16]. 